\title{
A versatile one-dimensional numerical model for packed-bed heat storage systems
}

\author{
Thibaut Esence ${ }^{\mathrm{a} *}$, Arnaud Bruch ${ }^{\mathrm{a}}$, Jean-François Fourmigué ${ }^{\mathrm{a}}$, Benoit Stutz ${ }^{\mathrm{b}}$ \\ ${ }^{a}$ Univ. Grenoble Alpes, CEA, LITEN, DTBH, Laboratoire de Stockage Thermique, F-38000 Grenoble, France \\ ${ }^{\mathrm{b}}$ LOCIE, Univ. Savoie, Campus Scientifique, Savoie Technolac, F-73376 Le Bourget-du-Lac Cedex, France \\ * thibaut.esence@laposte.net
}

5737 words (without captions, tables, nomenclature, references and appendix $=2285$ words)

\begin{abstract}
Thanks to their versatility and their relatively low cost, packed-bed sensible heat storage systems are promising for various applications like in central solar power plants, adiabatic compressed energy storage and pumped thermal energy storage. A versatile one-dimensional numerical model able to describe many packed-bed configurations is developed and presented. This model is able to treat liquid or gaseous heat transfer fluids. The packed bed can include a mixture of large and small solid particles such as rocks and sand, commonly encountered in the literature due to the advantages it procures. The model is compared and validated with specific experimental data and results from the literature covering wide ranges of configurations and operating conditions: several heat transfer fluids (molten salts, thermal oil, air), solid materials (rocks, sand, ceramics), fluid velocities, temperature levels and packed bed configurations are successfully tested. This shows the versatility of the developed model. The influence of the fluid velocity on heat losses, thermal diffusion and fluid/solid heat exchange are analysed. It enables to determine the optimal velocity which maximizes the performance of the storage system.
\end{abstract}

Keywords: Thermal energy storage, Packed bed, Thermocline, Porous medium, Numerical model, Fluid velocity influence.

\section{Introduction}

Packed-bed heat storage consists in storing sensible heat in a tank filled with a packed bed of solids. The storage is charged and discharged thanks to a heat transfer fluid, either liquid or gaseous, flowing through the bed in direct contact with the solids. The fluid usually flows from the top to the bottom during charge, and from the bottom to the top during discharge. This enables to improve thermal stratification by keeping the hot region at the top and the cold region at the bottom of the storage thanks to buoyancy forces. The two regions are separated by a transition zone called "thermocline". The thermocline thickness governs the exergy efficiency of the storage. It depends on several heat transfer interactions. This kind of heat storage system is relatively cost efficient and versatile (Brosseau et al., 2005; Cocco and Serra, 2015; Libby, 2010; Sabihuddin et al., 2015). It is therefore promising for heat storage in Concentrated Solar Power plants, adiabatic Compressed Air Energy Storage and Pumped Thermal Energy Storage systems. However, the behaviour and the performances of packed-bed heat storage systems depend on many heat transfer interactions which are difficult to describe using analytical approaches, especially during consecutive partial charge and discharge cycles. It is therefore necessary to use numerical models. The objective of this study is to develop a versatile model able to face the diversity of the applications and the designs of packedbed heat storage systems.

In the literature, several numerical models have been developed. Most of them are based on the energy equation applied to each component of the storage system: the solids, the heat transfer fluid and sometimes the wall of the tank. Each component with a dedicated energy equation is referred as a "phase". The models may be one-dimensional, two-dimensional or more rarely three-dimensional. Many models are based on the one-dimensional two-phase model developed by Schumann, 1929. In this model, the bed is assumed to be a continuous porous medium. The range of validity of this simple model is limited since it neglects the thermal resistance inside the solids, the heat diffusion in the bed and the influence of the tank's wall.

The thermal resistance due to conduction within the solids of the bed may be taken into account through an intra-particle conduction model: the heat equation is used in the discretised solids (Handley and Heggs, 1969). This approach is useful when the solids are not thermally thin $(\mathrm{Bi}<0.1)$ but requires more computing time. Another method enables to account for this thermal resistance while keeping the continuous medium approach. This is the extended lumped capacity method which consists in using an effective heat transfer coefficient which accounts for both convective and conductive thermal resistances (Xu et al., 2012).

Several phenomena lead to thermal de-stratification of the packed bed: conduction through the fluid and the solids, radiative heat transfer (when the fluid is transparent), fluid mixing, etc. These phenomena can be modelled as diffusion thanks to an effective thermal conductivity which enables to apply the Fourier's law (Van Antwerpen et al., 2010).

The influence of the tank's wall may be non-negligible, especially when the tank is small (Hoffmann et al., 2016). That's why some numerical models get an energy equation dedicated to the wall (Beasley and Clark, 1984; Hoffmann et al., 2016). This equation enables to compute the thermal profile of the wall and to account for the heat capacity and the axial conduction in the wall.

So far, the models of the literature have been validated thanks to experimental data but for specific configurations and operating conditions: either liquid or gaseous fluid, limited fluid velocity and temperature ranges... Moreover, no model has been developed to account for the specificities of packed beds with a bimodal particle size distribution consisting of a mixture 
of rocks and sand (Esence et al., 2017). This kind of packed bed is however commonly used since it enables to increase the volume fraction of solid filler in the bed, which reduces the cost or improves the heat capacity of the storage (Bruch et al., 2014; Hallet and Gervais, 1977; McDonnell Douglas Astronautics Company, 1986; Pacheco et al., 2002). The aim of this paper is to propose a versatile one-dimensional numerical model able to describe the thermal behaviour of many packed-bed configurations without fitting or adjustment. First, the model is described and the correlations used to compute the heat transfer coefficients in each case (monomodal or bimodal particle size distribution) are detailed. Second, the model is compared to three experimental setups with different heat transfer fluids (molten salts, air and oil) in various experimental conditions (flow and temperature). When possible, the results are compared through several charge/discharge cycles in order to strengthen the validation. Third, the validated model is used to carry out a numerical study of the fluid velocity influence. This study shows how such a model may be used to size and design packed-bed heat storage systems.

\section{Numerical model}

The behaviour and the performances of a packed-bed heat storage system depend on various phenomena (Fig. 1) which have to be accounted for in the numerical model. The developed model is able to treat packed beds with either monomodal or bimodal particle size distribution, either liquid or gaseous heat transfer fluid in a large range of operating conditions. General correlations are used to compute the heat transfer coefficients to keep the model as versatile as possible. The correlations are chosen depending on the structure of the packed bed only (monomodal or bimodal particle size distribution).

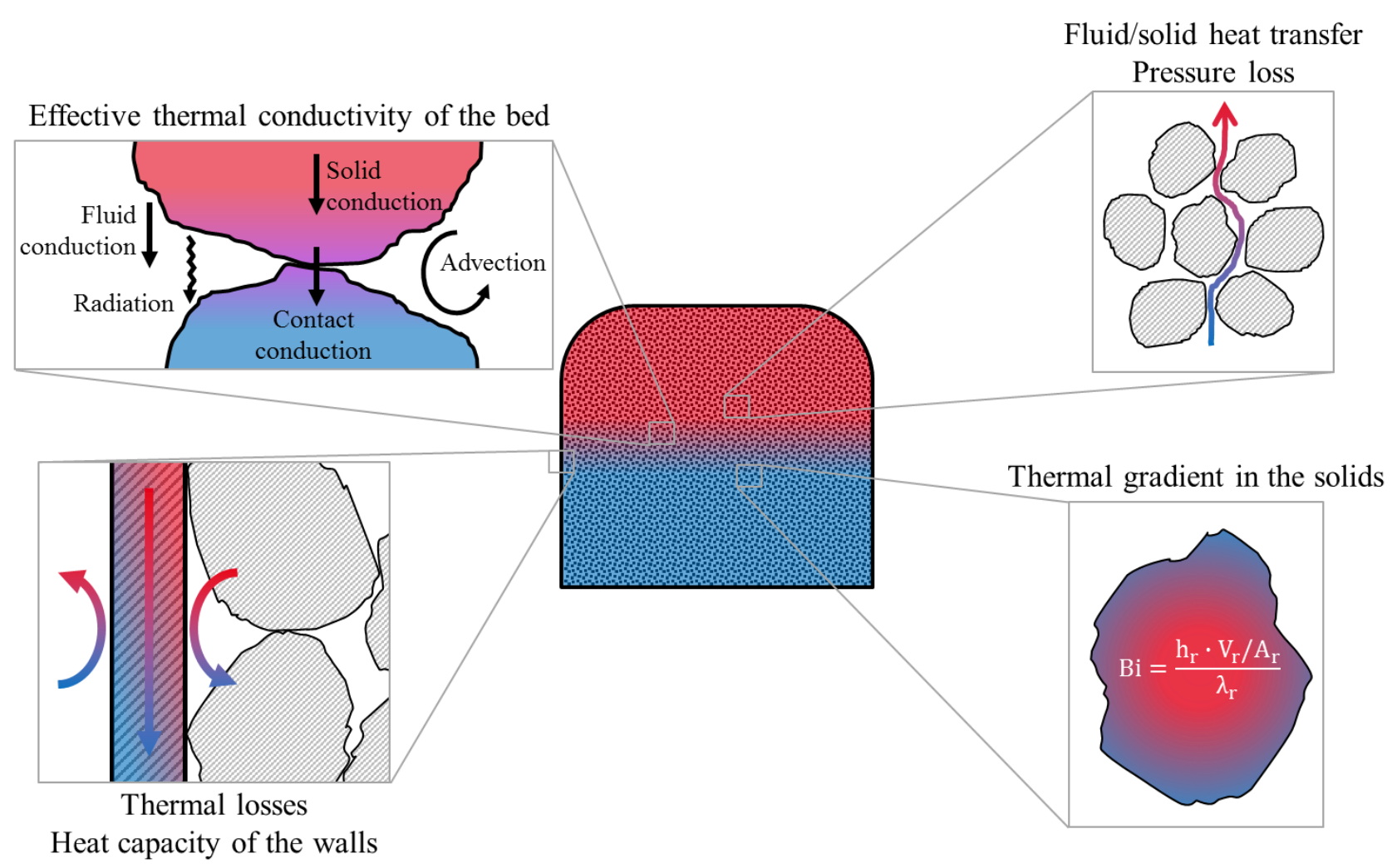

Axial conduction in the walls

Fig. 1. Diagram of some physical phenomena involved in the packed-bed storage behaviour.

\subsection{Governing equations}

The packed bed is modelled as a continuous porous medium. The one-dimensional numerical model consists of one continuity equation (1) for mass conservation of the fluid and three energy equations for the fluid (2), the solid filler (3) and the walls of the tank (4).

The enthalpy of the fluid is assumed to depend only on the temperature. This assumptions is common and reasonable for liquids. This assumption is also reasonable for gaseous heat transfer fluids since all the systems with a gaseous fluid investigated so far run near ambient pressure and with low pressure drop to limit the pumping costs of a compressible fluid (Esence et al., 2017). However, if the system ran at high pressure with significant pressure drop, the model would have to be adapted.

The temperature difference between the heat transfer fluid and the solid particles decreases with the decrease in the particles' diameter. This is due to the increase in the specific heat transfer surface and the heat transfer coefficient (through the reduction of the permeability and hence the hydraulic diameter). The particles' diameter below which the temperature difference can be neglected can be estimated thanks to the characteristic time of thermal conduction within the particle $t_{c o n d}=D_{s}{ }^{2} /\left(36 \cdot \alpha_{s}\right)$ and the characteristic time of thermal advection within the fluid $t_{a d v}=D_{s} / u_{f}$. The temperature difference between the heat transfer fluid and the particles can be considered negligible when $t_{c o n d}$ is significantly lower than $t_{a d v}$. This is usually the case for sand grains. They can therefore be considered at thermal equilibrium with the fluid, i.e. at the same 
temperature as the fluid $\left(T_{f}\right)$. Their heat capacity can be accounted for in the energy equation of the fluid. When there is no sand (monomodal particle size distributions), the volume fraction $x_{s}$ is zero and the corresponding term simply disappears.

The volume fractions $x_{r}, x_{s}$ and $x_{w}$ are defined as the volume of the considered species compared to the bed volume, i.e. the internal volume of the tank. As a result, $\varepsilon+x_{r}+x_{s}=1$ and $\varepsilon+x_{r}+x_{s}+x_{w} \geq 1$.

$$
\begin{aligned}
& \frac{\partial \rho_{\mathrm{f}}}{\partial \mathrm{t}}+\frac{\partial\left(\rho_{\mathrm{f}} \cdot \mathrm{u}_{\mathrm{f}}\right)}{\partial \mathrm{z}}=0 \\
& \frac{\partial\left(\varepsilon \cdot \rho_{\mathrm{f}} \cdot \mathrm{c}_{\mathrm{p}_{\mathrm{f}}} \cdot \mathrm{T}_{\mathrm{f}}\right)}{\partial \mathrm{t}}+\frac{\partial\left(\mathrm{x}_{\mathrm{s}} \cdot \rho_{\mathrm{s}} \cdot \mathrm{c}_{\mathrm{p}_{\mathrm{s}}} \cdot \mathrm{T}_{\mathrm{f}}\right)}{\partial \mathrm{t}}+\frac{\partial\left(\varepsilon \cdot \rho_{\mathrm{f}} \cdot \mathrm{u}_{\mathrm{f}} \cdot \mathrm{c}_{\mathrm{p}_{\mathrm{f}}} \cdot \mathrm{T}_{\mathrm{f}}\right)}{\partial \mathrm{z}} \\
& =\frac{\partial}{\partial \mathrm{z}}\left(\lambda_{\mathrm{eff}, \mathrm{f}+\mathrm{s}} \cdot \frac{\partial \mathrm{T}_{\mathrm{f}}}{\partial \mathrm{z}}\right)+\mathrm{h}_{\mathrm{eff}, \mathrm{r}} \cdot \mathrm{a}_{\mathrm{r}} \cdot\left(\mathrm{T}_{\mathrm{r}}-\mathrm{T}_{\mathrm{f}}\right)+\mathrm{h}_{\mathrm{eff}, \mathrm{w}} \cdot \mathrm{a}_{\mathrm{b}} \cdot\left(\mathrm{T}_{\mathrm{w}}-\mathrm{T}_{\mathrm{f}}\right) \\
& \frac{\partial\left(\mathrm{x}_{\mathrm{r}} \cdot \rho_{\mathrm{r}} \cdot \mathrm{c}_{\mathrm{p}_{\mathrm{r}}} \cdot \mathrm{T}_{\mathrm{r}}\right)}{\partial \mathrm{t}}=\frac{\partial}{\partial \mathrm{z}}\left(\lambda_{\mathrm{eff}, \mathrm{r}} \cdot \frac{\partial \mathrm{T}_{\mathrm{r}}}{\partial \mathrm{z}}\right)+\mathrm{h}_{\mathrm{eff}, \mathrm{r}} \cdot \mathrm{a}_{\mathrm{r}} \cdot\left(\mathrm{T}_{\mathrm{f}}-\mathrm{T}_{\mathrm{r}}\right) \\
& \frac{\partial\left(\mathrm{x}_{\mathrm{w}} \cdot \rho_{\mathrm{w}} \cdot \mathrm{c}_{\mathrm{p}_{\mathrm{w}}} \cdot \mathrm{T}_{\mathrm{w}}\right)}{\partial \mathrm{t}}=\frac{\partial}{\partial \mathrm{z}}\left(\mathrm{x}_{\mathrm{w}} \cdot \lambda_{\mathrm{w}} \cdot \frac{\partial \mathrm{T}_{\mathrm{w}}}{\partial \mathrm{z}}\right)+\mathrm{x}_{\mathrm{w}} \cdot \mathrm{h}_{\mathrm{eff}, \mathrm{w}} \cdot \mathrm{a}_{\mathrm{w}, \text { int }} \cdot\left(\mathrm{T}_{\mathrm{f}}-\mathrm{T}_{\mathrm{w}}\right)+\mathrm{x}_{\mathrm{w}} \cdot \mathrm{U}_{\mathrm{w} / \infty} \cdot \mathrm{a}_{\mathrm{w}, \mathrm{ext}} \cdot\left(\mathrm{T}_{\infty}-\mathrm{T}_{\mathrm{w}}\right)
\end{aligned}
$$

\subsection{Heat transfer coefficients for monomodal particle size distributions}

When there is no sand and all the particles have almost the same size, the total surface of solid per unit bed volume $a_{r}$ is calculated with equation (5) and the Nusselt number for convective heat transfer coefficient $h_{r}$ between the fluid and the solids is calculated with the correlation of Wakao et al., 1979 (6). This equation widely used in the literature was discussed in Esence et al., 2017: it accounts only for convection and is adapted to granular packed beds of uniformly sized spheroidal particles. To implement this correlation, the Reynolds number is calculated with equation (7). Thanks to the convective coefficient, the effective heat transfer coefficient $h_{e f f, r}$, which accounts for the internal conduction resistance of the particles, is calculated with equation (8) from Xu et al., 2012. This equation was developed for spherical shapes, therefore it can be reasonably used for spheroidal particles. The effective heat transfer coefficient enables the model to treat also non-thermally thin particles, i.e. with a Biot number superior to 0.1 .

$$
\begin{gathered}
\mathrm{a}_{\mathrm{r}}=\frac{6 \cdot(1-\varepsilon)}{\mathrm{D}_{\mathrm{eq}, \mathrm{a}, \mathrm{r}}} \\
\mathrm{Nu}_{\mathrm{r}}=\frac{\mathrm{h}_{\mathrm{r}} \cdot \mathrm{D}_{\mathrm{eq}, \mathrm{A}, \mathrm{r}}}{\lambda_{\mathrm{f}}}=2+1.1 \cdot \mathrm{Re}_{\mathrm{r}}^{0.6} \cdot \mathrm{Pr}^{1 / 3} \\
\operatorname{Re}_{\mathrm{r}}=\frac{\rho_{\mathrm{f}} \cdot \varepsilon \cdot \mathrm{u}_{\mathrm{f}} \cdot \mathrm{D}_{\mathrm{eq}, \mathrm{a}, \mathrm{r}}}{\mu_{\mathrm{f}}} \\
\frac{1}{\mathrm{~h}_{\mathrm{eff}, \mathrm{r}}}=\frac{1}{\mathrm{~h}_{\mathrm{r}}}+\frac{\mathrm{D}_{\mathrm{eq}, \mathrm{V}, \mathrm{r}}}{10 \cdot \lambda_{\mathrm{r}}}
\end{gathered}
$$

The convective heat transfer coefficient between the fluid circulating through the bed and the walls of the tank $h_{w}$ is calculated with the correlation of Dixon et al., 1984 (9) which was previously discussed in Esence et al., 2017. For cylindrical tanks, the internal conduction resistance of the walls is accounted for in the effective fluid/wall heat transfer coefficient $h_{\text {eff, } w}$ thanks to equation (10) from Xu et al., 2012.

$$
\begin{gathered}
\mathrm{Nu}_{\mathrm{w}}=\frac{\mathrm{h}_{\mathrm{w}} \cdot \mathrm{D}_{\mathrm{eq}, \mathrm{A}, \mathrm{r}}}{\lambda_{\mathrm{f}}}=\left[1-1.5 \cdot\left(\frac{\mathrm{D}_{\mathrm{eq}, \mathrm{V}, \mathrm{r}}}{\mathrm{D}_{\mathrm{b}}}\right)^{1.5}\right] \cdot \mathrm{Re}_{\mathrm{r}}{ }^{0.59} \cdot \operatorname{Pr}^{1 / 3} \\
\frac{1}{\mathrm{~h}_{\mathrm{eff}, \mathrm{w}}}=\frac{1}{\mathrm{~h}_{\mathrm{w}}}+\frac{1}{\lambda_{\mathrm{w}}} \cdot \frac{\mathrm{R}_{\mathrm{b}}{ }^{3} \cdot\left[4 \cdot\left(\mathrm{R}_{\mathrm{b}}+\mathrm{e}_{\mathrm{w}}\right)^{2}-\mathrm{R}_{\mathrm{b}}{ }^{2}\right]+\mathrm{R}_{\mathrm{b}} \cdot\left(\mathrm{R}_{\mathrm{b}}+\mathrm{e}_{\mathrm{w}}\right)^{4} \cdot\left[4 \cdot \ln \left(1+\frac{\mathrm{e}_{\mathrm{w}}}{\mathrm{R}_{\mathrm{b}}}\right)-3\right]}{4 \cdot\left[\left(\mathrm{R}_{\mathrm{b}}+\mathrm{e}_{\mathrm{w}}\right)^{2}-\mathrm{R}_{\mathrm{b}}{ }^{2}\right]^{2}}
\end{gathered}
$$


The diameters of the different equivalent spheres are necessary to compute all these equations. They are easy to define when the solids have regular shapes. It is however more difficult for irregular shapes. In that case, the diameters of the different equivalent spheres can be expressed thanks to the diameter of the sphere of equivalent volume $D_{e q, V, r}$ (which is easy to measure experimentally) and the sphericity $\Psi_{r}$ (cf. Appendix A).

\subsection{Heat transfer coefficients for bimodal particle size distributions}

For bimodal particle size distributions (i.e. when there are relatively big solids and fine particles, usually rocks and sand), the total surface of rock is calculated with equation (11). The convective heat transfer between the rocks and the fluid circulating through the sand is assumed to be similar to the convective heat transfer between the fluid flowing in a pipe filled by sand and the wall of the pipe. As a consequence, the correlation (12) from Dixon et al., 1984, is used for both fluid/solid and fluid/wall convective heat transfer coefficients. In that case, the characteristic diameter of the sand grains $D_{s}$ is used and the characteristic diameter of the voids filled by the sand between the rocks is estimated to be $D_{e q, V, r} / 2$. In this correlation, the Reynolds number characterizes the fluid flow through the sand and is calculated with equation (13). The effective heat transfer coefficients are calculated with equations (8) and (10) respectively for the solids and the wall.

$$
\begin{gathered}
\mathrm{a}_{\mathrm{r}}=\frac{6 \cdot\left(1-\varepsilon-\mathrm{x}_{\mathrm{s}}\right)}{\mathrm{D}_{\mathrm{eq}, \mathrm{a}, \mathrm{r}}} \\
\mathrm{Nu}=\frac{\mathrm{h}_{\mathrm{r}} \cdot \mathrm{D}_{\mathrm{s}}}{\lambda_{\mathrm{f}}}=\frac{\mathrm{h}_{\mathrm{w}} \cdot \mathrm{D}_{\mathrm{s}}}{\lambda_{\mathrm{f}}}=\left[1-1.5 \cdot\left(\frac{\mathrm{D}_{\mathrm{s}}}{\mathrm{D}_{\mathrm{eq}, \mathrm{V}, \mathrm{r}} / 2}\right)^{1.5}\right] \cdot \mathrm{Re}_{\mathrm{s}}{ }^{0.59} \cdot \operatorname{Pr}^{1 / 3} \\
\operatorname{Re}_{\mathrm{s}}=\frac{\varepsilon}{\varepsilon+\mathrm{x}_{\mathrm{s}}} \cdot \frac{\rho_{\mathrm{f}} \cdot \mathrm{u}_{\mathrm{f}} \cdot \mathrm{D}_{\mathrm{s}}}{\mu_{\mathrm{f}}}
\end{gathered}
$$

\subsection{Effective thermal conductivity}

Several phenomena lead to thermal de-stratification, i.e. thickening of the thermocline. These phenomena may be modelled as diffusion thanks to an effective thermal conductivity which enables to apply the Fourier's law. The effective thermal conductivity accounts for heat conduction in both phases (fluid and solids), heat diffusion due to mixing of the fluid and radiative heat transfer between neighbouring particles (only when the fluid is assumed transparent i.e. gaseous). Heat conduction through contact surfaces between particles can be neglected since the conductivity ratio between fluid and solid materials is usually less than $10^{3}$ (Hsu et al., 1994).

The effective thermal conductivity due to heat conduction in both phases $\lambda^{0}$ eff is calculated thanks to the correlation of Zehner and Schlünder, 1970, given by equation (14) or equation (15) if $\lambda_{f} B / \lambda_{r}=1$. In both equations, the parameter $B$ is given by equation (16). The constant $C$ is 1.25 for spherical particles or 1.4 for crushed solids. Equations (14), (15) and (16) are written for a monomodal particle size distribution configuration.

When there is sand, the equations (14) or (15) and (16) are applied twice: first with $\lambda_{s}$ instead of $\lambda_{r}$ and $\varepsilon /\left(\varepsilon+x_{s}\right)$ instead of $\varepsilon$ to get the effective conductivity $\lambda_{f+s}$ of the mixture of fluid and sand in the voids between the rocks; second, with $\lambda_{f+s}$ instead of $\lambda_{f}$ and $\left(\varepsilon+x_{s}\right)$ instead of $\varepsilon$ to get the overall effective conductivity $\lambda^{0}$ eff of the packed bed (fluid, sand and rocks). This means that the mixture of fluid and sand is assumed to be an effective fluid between the rocks with its own thermal conductivity $\lambda_{f+s}$.

$$
\begin{gathered}
\frac{\lambda_{\text {eff }}^{0}}{\lambda_{\mathrm{f}}}=1-\sqrt{1-\varepsilon}+\frac{2 \cdot \sqrt{1-\varepsilon}}{1-\frac{\lambda_{\mathrm{f}}}{\lambda_{\mathrm{r}}} \cdot \mathrm{B}} \cdot\left[\frac{\left(1-\frac{\lambda_{\mathrm{f}}}{\lambda_{\mathrm{r}}}\right) \cdot \mathrm{B}}{\left(1-\frac{\lambda_{\mathrm{f}}}{\lambda_{\mathrm{r}}} \cdot \mathrm{B}\right)^{2}} \cdot \ln \left(\frac{\lambda_{\mathrm{r}}}{\mathrm{B} \cdot \lambda_{\mathrm{f}}}\right)-\frac{\mathrm{B}+1}{2}-\frac{\mathrm{B}-1}{1-\frac{\lambda_{\mathrm{f}}}{\lambda_{\mathrm{r}}} \cdot \mathrm{B}}\right] \\
\frac{\lambda_{\mathrm{eff}}^{0}}{\lambda_{\mathrm{f}}}=1-\sqrt{1-\varepsilon}+\sqrt{1-\varepsilon} \cdot \frac{1+2 \cdot \mathrm{B}^{3}-3 \cdot \mathrm{B}^{2}}{3 \cdot(\mathrm{B}-1)^{2}} \\
\mathrm{~B}=\frac{\mathrm{C} \cdot(1-\varepsilon)^{10 / 9}}{\varepsilon}
\end{gathered}
$$

The effective conductivity of the bed due to conduction $\lambda^{0}$ eff is separated into the effective conductivity of the solid phase $\lambda^{0}{ }_{e f f, r}$ and the effective conductivity of the fluid phase or the mixture of fluid and sand $\lambda^{0} e_{e f f, f(+s)}$. For that purpose, the conductive heat fluxes through the fluid and the solids are assumed parallel and the thermal gradient $\partial T / \partial z$ of each phase is assumed the same. This leads to equations (17) and (18) in which the tortuosity $f$ is given by equation (19). For bimodal particle size distributions, $\varepsilon$ and $\lambda_{f}$ have to be replaced respectively by $\left(\varepsilon+x_{s}\right)$ and $\lambda_{f+s}$ in equations (17), (18) and (19).

$$
\lambda_{\mathrm{eff}, \mathrm{f}}^{0}=(\varepsilon+\mathrm{f}) \cdot \lambda_{\mathrm{f}}
$$




$$
\begin{gathered}
\lambda_{\text {eff,r }}^{0}=(1-\varepsilon-f) \cdot \lambda_{r} \\
\mathrm{f}=\frac{\lambda_{\text {eff }}^{0}-\varepsilon \cdot \lambda_{\mathrm{f}}-(1-\varepsilon) \cdot \lambda_{\mathrm{r}}}{\lambda_{\mathrm{f}}-\lambda_{\mathrm{r}}}
\end{gathered}
$$

The mixing contribution is then accounted for in the effective conductivity of the fluid with the correlation of Wakao and Kaguei, 1982 (equation (20)). In this equation, $R e_{r}$ has to be replaced by $\operatorname{Re}_{s}$ (see equation (13)) for bimodal particle size distributions.

$$
\lambda_{\mathrm{eff}, \mathrm{f}}=\lambda_{\mathrm{eff}, \mathrm{f}}^{0}+0,5 \cdot \lambda_{\mathrm{f}} \cdot \mathrm{Re}_{\mathrm{r}} \cdot \operatorname{Pr}
$$

Radiation between particles is accounted for in the effective conductivity of the solid phase with the correlation of Breitbach and Barthels, 1980 (equation (21)). The radiative contribution should be accounted for only when the fluid is transparent i.e. gaseous. Usually, there is no sand when the fluid is gaseous, therefore equation (21) needn't be adapted for bimodal particle size distributions. Since the fluid is usually liquid and assumed opaque when there is sand, $\lambda_{e f f, r}=\lambda_{e f f, r}^{0}$.

$$
\lambda_{\mathrm{eff}, \mathrm{r}}=\lambda_{\mathrm{eff}, \mathrm{r}}^{0}+\left[(1-\sqrt{1-\varepsilon}) \cdot \varepsilon+\frac{\sqrt{1-\varepsilon}}{\frac{2}{\epsilon_{\mathrm{r}}}-1} \cdot \frac{\mathrm{B}+1}{\mathrm{~B}} \cdot \frac{1}{1+\frac{1}{\left(\frac{2}{\epsilon_{\mathrm{r}}}-1\right) \cdot \frac{\lambda_{\mathrm{r}}}{4 \cdot \sigma \cdot \mathrm{Tr}_{\mathrm{r}}^{3} \cdot \mathrm{D}_{\mathrm{eq}, \mathrm{a}, \mathrm{r}}}}}\right] \cdot 4 \cdot \sigma \cdot \mathrm{T}_{\mathrm{r}}^{3} \cdot \mathrm{D}_{\mathrm{eq}, \mathrm{a}, \mathrm{r}}
$$

\subsection{Numerical method}

The model is discretized with the finite volume approach. The diffusive and the advective terms are respectively treated thanks to the central differencing and the Quadratic Upstream Interpolation for Convective Kinematics (QUICK) schemes. The model is computed with the implicit Euler method. For each simulation, the number of elementary volumes and the time step duration were chosen so that they didn't affect significantly the results.

When the fluid is liquid, it flows slowly (at some $\mathrm{mm} / \mathrm{s}$ ) and its properties undergo little variations. Therefore, the system of equations is quasi-linear and can be solved efficiently with the Cramer's rule providing some iterations. When the fluid is gaseous, it usually flows at high velocity (up to several $\mathrm{m} / \mathrm{s}$ ) and its properties may vary significantly with temperature. Consequently, a linear method is no longer efficient, that's why the Newton-Raphson method is used to solve the system of equations. It has been checked that both methods lead to similar results, i.e. with a difference of the same order of magnitude as the convergence criteria.

\section{Model validation}

The results of the numerical model have been compared to experimental results from numerous setups of the literature and from setups operated by the French Atomic Energy Commission (CEA). In this paper, three experimental validations of the model are presented: two with setups from the literature (Cascetta et al., 2016; Pacheco et al., 2002) and one with the STONE experimental loop operated by the CEA (Bruch et al., 2014, 2017). These comparisons aim to show the versatility of the model.

\subsection{Validation with the results of Pacheco}

The prototype operated by Pacheco et al., 2002, is a 40- $\mathrm{m}^{3}$ and 2.3- $\mathrm{MWh}_{\text {th }}$ packed-bed storage system. The packed bed consists of a mixture of quarzitic rocks and silica sand (bimodal particle size distribution) and the heat transfer fluid consists of molten salts $\left(50 \%\right.$ wt $\mathrm{NaNO}_{3}+50 \%$ wt $\left.\mathrm{KNO}_{3}\right)$. One discharge from $396^{\circ} \mathrm{C}$ to $290^{\circ} \mathrm{C}$ is published by the authors but the thermal profiles are particularly scattered for unexplained reasons and the operating conditions, mainly the flow rate of fluid, are not given.

The inlet fluid velocity and hence the mass flow rate was estimated by Flueckiger et al., 2014, from the average thermal front velocity, i.e. the velocity of the thermocline through the packed bed during the discharge process. The fluid velocity and the thermal front velocity are related by the ratio between the volumetric heat capacity of fluid and the volumetric heat capacity of the whole storage system. In their calculation, Flueckiger et al., 2014, neglect the contribution of the tank's wall in the heat capacity of the storage. Therefore, the mass flow rate calculated with this method is not suitable for a numerical model in which the tank's wall is accounted for. As far as the authors know, there is no available data in the literature concerning the characteristics of the walls. Furthermore, the walls get heat trace to make up thermal losses and to maintain the molten salts at liquid state during standby periods. For these reasons, the heat capacity of the walls and the thermal losses are assumed negligible. Therefore, the energy equation of the walls is useless and the storage system can be modelled with only two energy equations (fluid and solids) and one continuity equation. The mass flow rate calculated by Flueckiger et al., 2014, is adopted 
and the model is initialized with the first available thermal profile (11h30 in Fig. 2). The other parameters of the simulation are listed in Table 1.

In this case, $t_{\text {cond }}$ is approximately 30 times lower than $t_{a d v}$ for the sand grains. It is therefore reasonable to assume thermal equilibrium between the sand and the molten salts in accordance with equation (2).

The comparison between experimental and numerical results is shown in Fig. 2. In spite of the scattering of the experimental thermal profiles, this figure shows that the model is able to describe the overall behaviour of the system.

\begin{tabular}{|c|c|c|}
\hline \multicolumn{2}{|r|}{ Simulation parameters } & Sources \\
\hline \multicolumn{3}{|l|}{ Packed bed } \\
\hline $\mathrm{L}_{\mathrm{b}}[\mathrm{m}]$ & 5.2 & Pacheco et al., 2002 \\
\hline $\mathrm{D}_{\mathrm{b}}[\mathrm{m}]$ & 3.0 & Pacheco et al., 2002 \\
\hline \multicolumn{2}{|c|}{ Fluid: $50 \%$ wt $\mathrm{NaNO}_{3}+50 \%$ wt $\mathrm{KNO}_{3}$} & Pacheco et al., 2002 \\
\hline$\varepsilon$ & 0.22 & Pacheco et al., 2002 \\
\hline$\rho_{\mathrm{f}}\left[\mathrm{kg} \cdot \mathrm{m}^{-3}\right]$ & $-0.636 \cdot \mathrm{T}\left({ }^{\circ} \mathrm{C}\right)+2090.000$ & Nissen, 1982 \\
\hline $\mathrm{c}_{\mathrm{p}_{\mathrm{f}}}\left[\mathrm{J} \cdot \mathrm{kg}^{-1} \cdot \mathrm{K}^{-1}\right]$ & $0.172 \cdot \mathrm{T}\left({ }^{\circ} \mathrm{C}\right)+1443.000$ & Nissen, 1982 \\
\hline$\lambda_{\mathrm{f}}\left[\mathrm{W} \cdot \mathrm{m}^{-1} \cdot \mathrm{K}^{-1}\right]$ & $-0.00019 \cdot \mathrm{T}\left({ }^{\circ} \mathrm{C}\right)+0.44300$ & Nissen, 1982 \\
\hline$\mu_{\mathrm{f}}[\mathrm{Pa} \cdot \mathrm{s}]$ & $-1.474 \cdot 10^{-10} \cdot \mathrm{T}\left({ }^{\circ} \mathrm{C}\right)^{3}+2.281 \cdot 10^{-7} \cdot \mathrm{T}\left({ }^{\circ} \mathrm{C}\right)^{2}-1.2 \cdot 10^{-4} \cdot \mathrm{T}\left({ }^{\circ} \mathrm{C}\right)+2.2714 \cdot 10^{-2}$ & Nissen, 1982 \\
\hline \multicolumn{2}{|c|}{ Rocks: Quartzite } & Pacheco et al., 2002 \\
\hline $\mathrm{X}_{\mathrm{r}}$ & 0.54 & Pacheco et al., 2002 \\
\hline $\mathrm{D}_{\mathrm{eq}, \mathrm{V}, \mathrm{r}}[\mathrm{m}]$ & 0.019 & Pacheco et al., 2002 \\
\hline$\Psi_{\mathrm{r}}$ & 0.8 & Hypothesis \\
\hline$\rho_{\mathrm{r}}\left[\mathrm{kg} \cdot \mathrm{m}^{-3}\right]$ & 2500 & Flueckiger et al., 2014 \\
\hline $\mathrm{c}_{\mathrm{p}_{\mathrm{r}}}\left[\mathrm{J} \cdot \mathrm{kg}^{-1} \cdot \mathrm{K}^{-1}\right]$ & 830 & Flueckiger et al., 2014 \\
\hline$\lambda_{\mathrm{r}}\left[\mathrm{W} \cdot \mathrm{m}^{-1} \cdot \mathrm{K}^{-1}\right]$ & 5.0 & Flueckiger et al., 2014 \\
\hline \multicolumn{2}{|l|}{ Sand: Silica } & Pacheco et al., 2002 \\
\hline $\mathrm{X}_{\mathrm{S}}$ & 0.24 & Pacheco et al., 2002 \\
\hline $\mathrm{D}_{\mathrm{s}}[\mathrm{m}]$ & 0.0015 & Pacheco et al., 2002 \\
\hline$\rho_{\mathrm{s}}\left[\mathrm{kg} \cdot \mathrm{m}^{-3}\right]$ & 2500 & Similar to rocks \\
\hline $\mathrm{c}_{\mathrm{p}_{\mathrm{s}}}\left[\mathrm{J} \cdot \mathrm{kg}^{-1} \cdot \mathrm{K}^{-1}\right]$ & 830 & Similar to rocks \\
\hline$\lambda_{\mathrm{s}}\left[\mathrm{W} \cdot \mathrm{m}^{-1} \cdot \mathrm{K}^{-1}\right]$ & 5.0 & Similar to rocks \\
\hline \multicolumn{3}{|c|}{ Operating conditions } \\
\hline $\mathrm{T}_{\text {inlet }}\left[{ }^{\circ} \mathrm{C}\right]$ & 290 & Pacheco et al., 2002 \\
\hline$\left(\varepsilon \cdot \mathrm{u}_{\mathrm{f}}\right)_{\text {inlet }}\left[\mathrm{m} \cdot \mathrm{s}^{-1}\right]$ & $4.36 \cdot 10^{-4}$ & Flueckiger et al., 2014 \\
\hline$\dot{\mathrm{m}}\left[\mathrm{kg} \cdot \mathrm{s}^{-1}\right]$ & 5.873 & Calculation \\
\hline
\end{tabular}

Table 1. Parameters and correlations used for numerical simulation of the setup of Pacheco et al., 2002, during discharge.

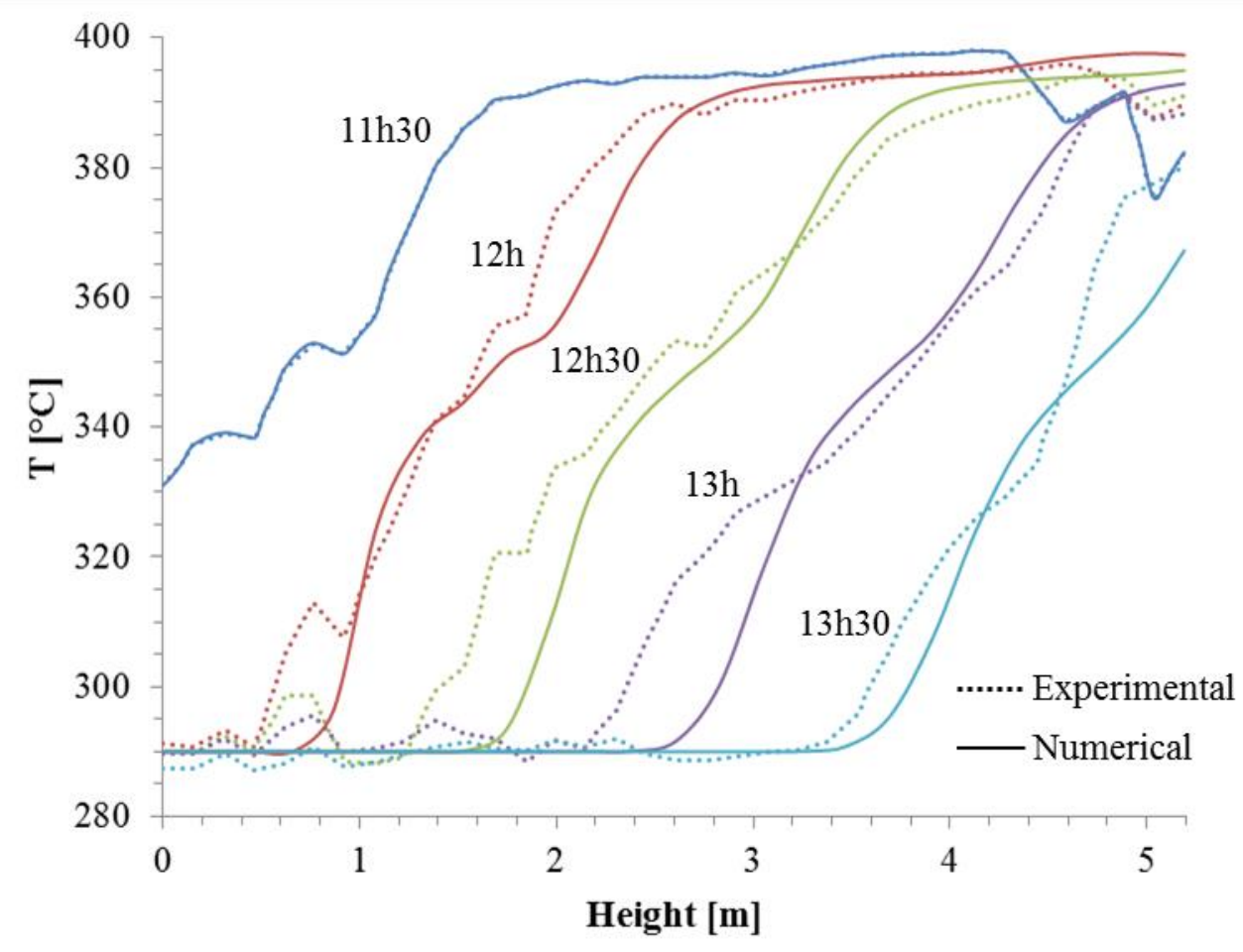

Fig. 2. Experimental results from Pacheco et al., 2002, during a discharge compared to the results of the numerical model.

\subsection{Validation with the results of Cascetta}


Cascetta et al., 2016, studied a packed-bed storage system consisting of alumina beads and running with air up to $240^{\circ} \mathrm{C}$ as heat transfer fluid. Numerous experimental tests have been published. One of them consists in a charge from an initially thermally uniform system and followed by a discharge. The mass flow rate during this test is constant and the evolution of the inlet fluid temperature versus the dimensionless time is reproduced in Fig. 3. For simulation purposes, the thickness of the walls has been estimated graphically thanks to a sectional drawing assumed scaled. The thermal loss coefficient has been calculated by considering $100 \mathrm{~mm}$ of thermal insulation with a thermal conductivity assumed to be $0.05 \mathrm{~W} \cdot \mathrm{m}^{-1} \cdot \mathrm{K}^{-1}$ and an external convective resistance assumed to be $0.13 \mathrm{~m} \mathrm{~m}^{2} \cdot \mathrm{K} \cdot \mathrm{W}^{-1}$. The thermal profile calculated at the end of the charge is used to initialize the consecutive discharge. All the parameters of the simulation are listed in Table 2.

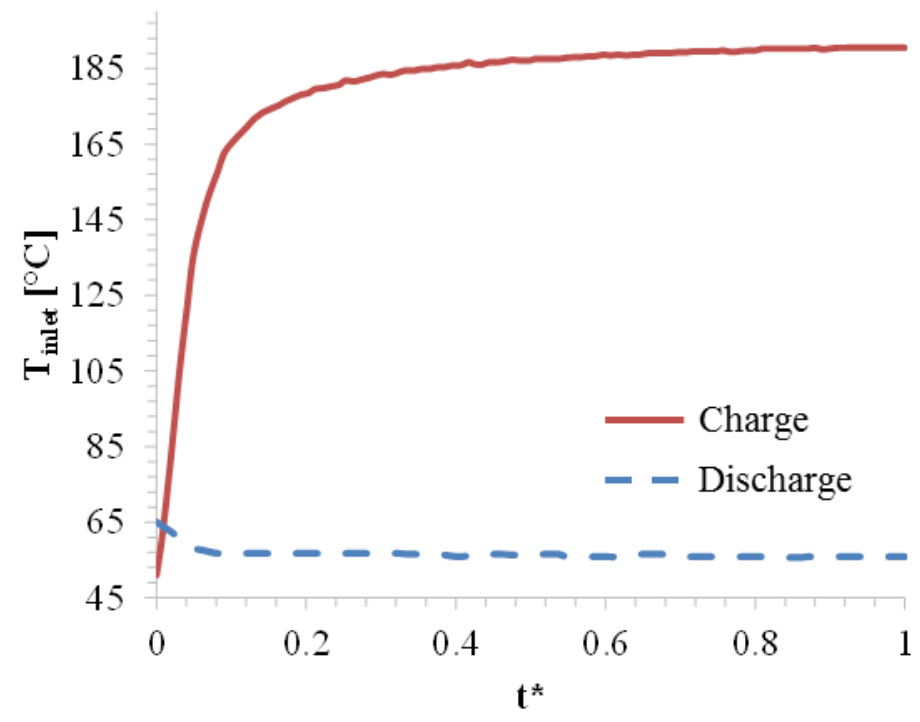

Fig. 3. Evolution of the inlet fluid temperature during the charge and the consecutive discharge of the setup (Cascetta et al., 2016).

\begin{tabular}{|c|c|c|}
\hline \multicolumn{2}{|r|}{ Simulation parameters } & Sources \\
\hline \multicolumn{3}{|l|}{ Packed bed } \\
\hline $\mathrm{L}_{\mathrm{b}}[\mathrm{m}]$ & 1.80 & Cascetta et al., 2016 \\
\hline $\mathrm{D}_{\mathrm{b}}[\mathrm{m}]$ & 0.584 & Cascetta et al., 2016 \\
\hline \multicolumn{2}{|l|}{ Fluid: Air } & Cascetta et al., 2016 \\
\hline$\varepsilon$ & 0.39 & Cascetta et al., 2016 \\
\hline$\rho_{\mathrm{f}}\left[\mathrm{kg} \cdot \mathrm{m}^{-3}\right]$ & $\begin{array}{l}101325 \cdot \mathrm{M} /(8.3145 \cdot \mathrm{T}(\mathrm{K})) \\
\mathrm{M}=0.028971 \mathrm{~kg} \cdot \mathrm{mol}^{-1}\end{array}$ & Standard value \\
\hline $\mathrm{c}_{\mathrm{p}_{\mathrm{f}}}\left[\mathrm{J} \cdot \mathrm{kg}^{-1} \cdot \mathrm{K}^{-1}\right]$ & $-2.3397 \cdot 10^{-7} \cdot \mathrm{T}(\mathrm{K})^{3}+5.5136 \cdot 10^{-4} \cdot \mathrm{T}(\mathrm{K})^{2}-0.19523 \cdot \mathrm{T}(\mathrm{K})+1019.9050$ & Standard value \\
\hline$\lambda_{\mathrm{f}}\left[\mathrm{W} \cdot \mathrm{m}^{-1} \cdot \mathrm{K}^{-1}\right]$ & $1.521 \cdot 10^{-11} \cdot \mathrm{T}(\mathrm{K})^{3}-4.857 \cdot 10^{-8} \cdot \mathrm{T}(\mathrm{K})^{2}+1.0184 \cdot 10^{-4} \cdot \mathrm{T}(\mathrm{K})-3.9333 \cdot 10^{-4}$ & Standard value \\
\hline$\mu_{\mathrm{f}}[\mathrm{Pa} \cdot \mathrm{s}]$ & $8.3592 \cdot 10^{-15} \cdot \mathrm{T}(\mathrm{K})^{3}-2.9800 \cdot 10^{-11} \cdot \mathrm{T}(\mathrm{K})^{2}+6.2772 \cdot 10^{-8} \cdot \mathrm{T}(\mathrm{K})+2.0863 \cdot 10^{-6}$ & Standard value \\
\hline \multicolumn{2}{|c|}{ Solids: Alumina beads } & Cascetta et al., 2016 \\
\hline $\mathrm{X}_{\mathrm{r}}$ & 0.62 & Cascetta et al., 2016 \\
\hline $\mathrm{D}_{\mathrm{eq}, \mathrm{V}, \mathrm{r}}[\mathrm{m}]$ & 0.008 & Cascetta et al., 2016 \\
\hline$\Psi_{\mathrm{r}}$ & 1 & Cascetta et al., 2016 \\
\hline$\rho_{\mathrm{r}}\left[\mathrm{kg} \cdot \mathrm{m}^{-3}\right]$ & 3550 & Cascetta et al., 2016 \\
\hline $\mathrm{c}_{\mathrm{p}_{\mathrm{r}}}\left[\mathrm{J} \cdot \mathrm{kg}^{-1} \cdot \mathrm{K}^{-1}\right]$ & 902 & Cascetta et al., 2016 \\
\hline$\lambda_{\mathrm{r}}\left[\mathrm{W} \cdot \mathrm{m}^{-1} \cdot \mathrm{K}^{-1}\right]$ & 30 & Cascetta et al., 2016 \\
\hline$\epsilon_{\mathrm{r}}$ & 0.8 & Standard value \\
\hline \multicolumn{2}{|c|}{ Walls: Carbon steel } & Cascetta et al., 2016 \\
\hline $\mathrm{e}_{\mathrm{w}}[\mathrm{m}]$ & 0.0075 & $\begin{array}{c}\text { Cascetta et al., } 2016 \\
\text { (graphically) }\end{array}$ \\
\hline$\rho_{\mathrm{w}}\left[\mathrm{kg} \cdot \mathrm{m}^{-3}\right]$ & 7850 & Standard value \\
\hline $\mathrm{c}_{\mathrm{p}_{\mathrm{w}}}\left[\mathrm{J} \cdot \mathrm{kg}^{-1} \cdot \mathrm{K}^{-1}\right]$ & 461 & Standard value \\
\hline$\lambda_{\mathrm{w}}\left[\mathrm{W} \cdot \mathrm{m}^{-1} \cdot \mathrm{K}^{-1}\right]$ & 51 & Standard value \\
\hline \multicolumn{3}{|l|}{ Thermal losses } \\
\hline $\mathrm{U}_{\mathrm{w} / \infty}\left[\mathrm{W} \cdot \mathrm{m}^{-2} \cdot \mathrm{K}^{-1}\right]$ & 0.55 & Calculation \\
\hline $\mathrm{T}_{\infty}\left[{ }^{\circ} \mathrm{C}\right]$ & 25 & Hypothesis \\
\hline \multicolumn{3}{|c|}{ Operating conditions during charge } \\
\hline $\mathrm{T}_{\text {inlet }}\left[{ }^{\circ} \mathrm{C}\right]$ & Function of time (cf. Fig. 3) & $\begin{array}{c}\text { Cascetta et al., } 2016 \\
\text { (graphically) }\end{array}$ \\
\hline$\dot{\mathrm{m}}\left[\mathrm{kg} \cdot \mathrm{s}^{-1}\right]$ & 0.20 & Cascetta et al., 2016 \\
\hline
\end{tabular}




\begin{tabular}{|l|l|c|}
\hline $\mathrm{T}_{\text {inlet }}\left[{ }^{\circ} \mathrm{C}\right]$ & Function of time (cf. Fig. 3) & $\begin{array}{c}\text { Cascetta et al., 2016 } \\
\text { (graphically) }\end{array}$ \\
\hline$\dot{\mathrm{m}}\left[\mathrm{kg} \cdot \mathrm{s}^{-1}\right]$ & 0.20 & Cascetta et al., 2016 \\
\hline
\end{tabular}

Table 2. Parameters and correlations used for numerical simulation of the setup of Cascetta et al., 2016.
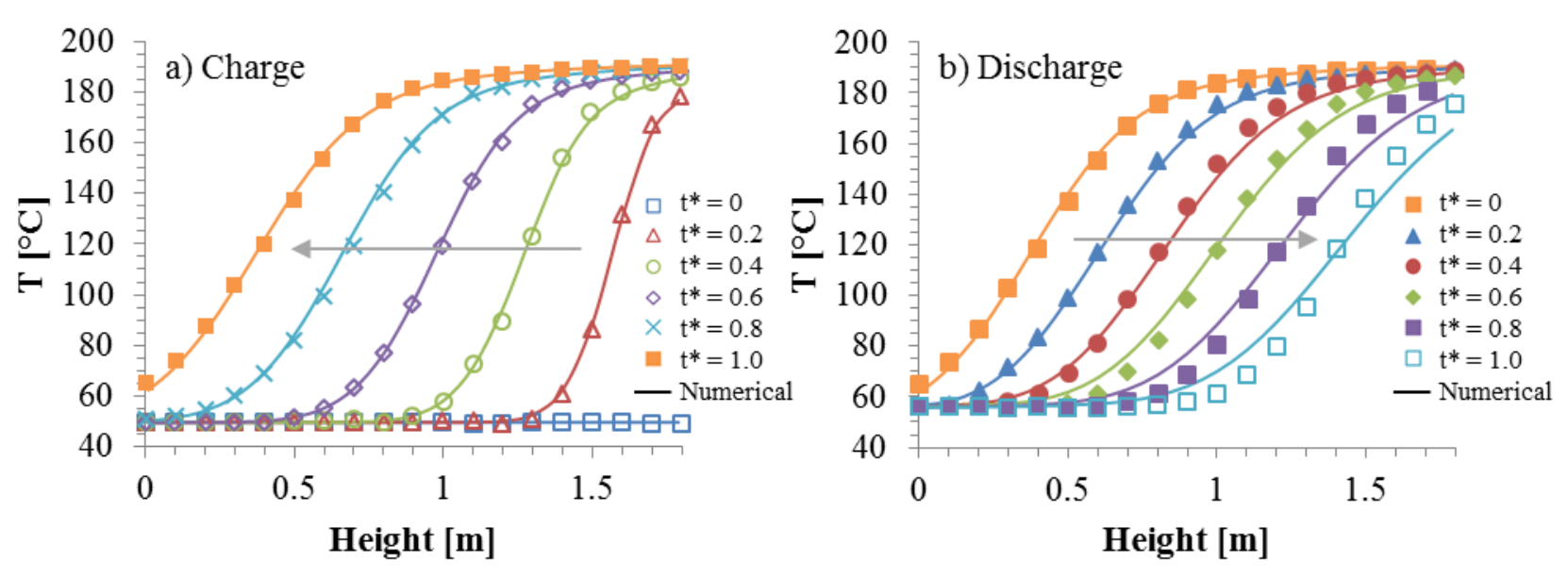

Fig. 4. Experimental results from Cascetta et al., 2016, compared to the results of the numerical model during a charge (a) and the consecutive discharge (b).

Fig. 4 (a) shows a very good agreement between experimental and numerical results. In Fig. 4 (b), the numerical results at the end of the discharge are not as good compared to experimental ones: the thermocline predicted by the model is thicker.

This may be due to inertial effects of the walls which are not correctly accounted for by the model: at the top of the tank there is a big uninsulated flange which is not modelled.

In Cascetta et al., 2016, all the data are given as a function of dimensionless time. According to the simulations the charge and the discharge processes last respectively $4245 \mathrm{~s}$ and $2795 \mathrm{~s}$. The effective durations of the experimental tests were graciously given by Mr. Cascetta: the tests last respectively $3985 \mathrm{~s}$ and $2700 \mathrm{~s}$. That means that the model is able to predict the real durations with an error of only $6.6 \%$ and $3.5 \%$ respectively.

\subsection{Validation with the STONE setup}

The STONE experimental loop operated by the French Atomic Energy Commission (CEA) consists of a cylindrical storage tank with a $2.4-\mathrm{m}^{3}$ packed bed of rock and sand with thermal oil up to $300{ }^{\circ} \mathrm{C}$ as heat transfer fluid. The storage is charged and discharged thanks to an electrical heater and air coolers respectively. The characteristics of the setup are listed in Table 3. The packed bed is instrumented with thermocouples placed both in the fluid and the rocks at various axial and radial positions. There are also thermocouples in the inlet/outlet pipes of the tank (Fig. 5). Experimental results and further details about the instrumentation are available in Bruch et al., 2014, 2017.

\begin{tabular}{|c|c|}
\hline \multicolumn{2}{|l|}{ Packed bed } \\
\hline $\mathrm{L}_{\mathrm{b}}[\mathrm{m}]$ & 3.0 \\
\hline $\mathrm{D}_{\mathrm{b}}[\mathrm{m}]$ & 1.0 \\
\hline \multicolumn{2}{|c|}{ Fluid: Therminol ${ }^{\circledR} 66$} \\
\hline$\varepsilon$ & 0.27 \\
\hline$\rho_{\mathrm{f}}\left[\mathrm{kg} \cdot \mathrm{m}^{-3}\right]$ & $-0.000321 \cdot \mathrm{T}\left({ }^{\circ} \mathrm{C}\right)^{2}-0.614254 \cdot \mathrm{T}\left({ }^{\circ} \mathrm{C}\right)+1020.62$ \\
\hline $\mathrm{c}_{\mathrm{p}_{\mathrm{f}}}\left[\mathrm{J} \cdot \mathrm{kg}^{-1} \cdot \mathrm{K}^{-1}\right]$ & $8.970785 \cdot 10^{-4} \cdot \mathrm{T}\left({ }^{\circ} \mathrm{C}\right)^{2}+3.313 \cdot \mathrm{T}\left({ }^{\circ} \mathrm{C}\right)+1496.005$ \\
\hline$\lambda_{\mathrm{f}}\left[\mathrm{W} \cdot \mathrm{m}^{-1} \cdot \mathrm{K}^{-1}\right]$ & $-1.5 \cdot 10^{-7} \cdot \mathrm{T}\left({ }^{\circ} \mathrm{C}\right)^{2}-3.3 \cdot 10^{-5} \cdot \mathrm{T}\left({ }^{\circ} \mathrm{C}\right)+0.118294$ \\
\hline$v_{\mathrm{f}}\left[\mathrm{m}^{2} \cdot \mathrm{s}^{-1}\right]$ & $\exp \left[586.375 /\left(\mathrm{T}\left({ }^{\circ} \mathrm{C}\right)+62.5\right)-2.2809\right] \cdot 10^{-6}$ \\
\hline \multicolumn{2}{|c|}{ Rocks: Quartzite } \\
\hline $\mathrm{x}_{\mathrm{r}}$ & 0.584 \\
\hline $\mathrm{D}_{\mathrm{eq}, \mathrm{V}, \mathrm{r}}[\mathrm{m}]$ & 0.0262 \\
\hline$\Psi_{\mathrm{r}}$ & 0.8 \\
\hline$\rho_{\mathrm{r}}\left[\mathrm{kg} \cdot \mathrm{m}^{-3}\right]$ & 2595 \\
\hline $\mathrm{c}_{\mathrm{p}_{\mathrm{r}}}\left[\mathrm{J} \cdot \mathrm{kg}^{-1} \cdot \mathrm{K}^{-1}\right]$ & $0.8841 \cdot \mathrm{T}\left({ }^{\circ} \mathrm{C}\right)+795.9$ \\
\hline$\lambda_{\mathrm{r}}\left[\mathrm{W} \cdot \mathrm{m}^{-1} \cdot \mathrm{K}^{-1}\right]$ & 5.5 \\
\hline \multicolumn{2}{|l|}{ Sand: Silica } \\
\hline $\mathrm{x}_{\mathrm{s}}$ & 0.146 \\
\hline $\mathrm{D}_{\mathrm{s}}[\mathrm{m}]$ & 0.0025 \\
\hline$\rho_{\mathrm{s}}\left[\mathrm{kg} \cdot \mathrm{m}^{-3}\right]$ & 2595 \\
\hline $\mathrm{c}_{\mathrm{p}_{\mathrm{s}}}\left[\mathrm{J} \cdot \mathrm{kg}^{-1} \cdot \mathrm{K}^{-1}\right]$ & $0.8841 \cdot \mathrm{T}\left({ }^{\circ} \mathrm{C}\right)+795.9$ \\
\hline$\lambda_{\mathrm{s}}\left[\mathrm{W} \cdot \mathrm{m}^{-1} \cdot \mathrm{K}^{-1}\right]$ & 5.5 \\
\hline \multicolumn{2}{|c|}{ Walls: Stainless steel AISI 316L } \\
\hline $\mathrm{e}_{\mathrm{w}}[\mathrm{m}]$ & 0.005 \\
\hline
\end{tabular}




\begin{tabular}{|l|l|}
\hline$\rho_{\mathrm{w}}\left[\mathrm{kg} \cdot \mathrm{m}^{-3}\right]$ & 7900 \\
\hline $\mathrm{c}_{\mathrm{p}_{\mathrm{W}}}\left[\mathrm{J} \cdot \mathrm{kg}^{-1} \cdot \mathrm{K}^{-1}\right]$ & $8 \cdot 10^{-7} \cdot \mathrm{T}\left({ }^{\circ} \mathrm{C}\right)^{3}-0.0011 \cdot \mathrm{T}\left({ }^{\circ} \mathrm{C}\right)^{2}+0.6136 \cdot \mathrm{T}\left({ }^{\circ} \mathrm{C}\right)+440.11$ \\
\hline$\lambda_{\mathrm{W}}\left[\mathrm{W} \cdot \mathrm{m}^{-1} \cdot \mathrm{K}^{-1}\right]$ & $0.0125 \cdot \mathrm{T}\left({ }^{\circ} \mathrm{C}\right)+11.0$ \\
\hline Thermal losses & \\
\hline $\mathrm{U}_{\mathrm{w} / \infty}\left[\mathrm{W} \cdot \mathrm{m}^{-2} \cdot \mathrm{K}^{-1}\right]$ & 1.55 \\
\hline $\mathrm{T}_{\infty}\left[{ }^{\circ} \mathrm{C}\right]$ & $\sim 15^{\circ} \mathrm{C}$ \\
\hline
\end{tabular}

Table 3. Parameters and correlations used for numerical simulation of the STONE setup.

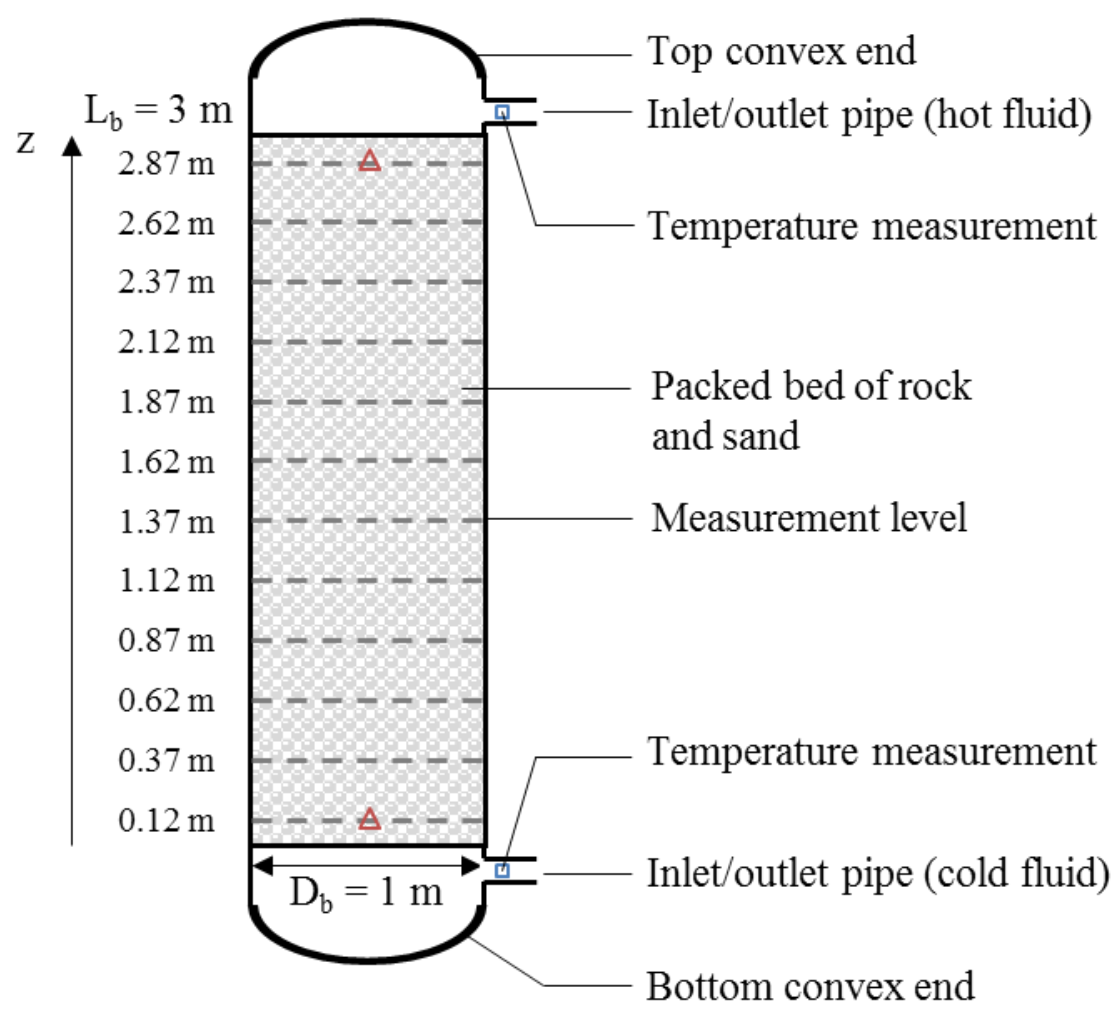

Fig. 5. Diagram of the storage tank of STONE.

With the maximum fluid velocity of the experimental tests $(4.0 \mathrm{~mm} / \mathrm{s}), t_{c o n d}$ of the sand grains is 8.5 times lower than $t_{a d v}$. It is therefore reasonable to assume thermal equilibrium between the sand and the oil in accordance with equation (2).

For modelling, it is necessary to know the evolution of the fluid temperature at the inlet of the bed. There are thermocouples in the inlet/outlet pipes of the tank (marked with squares on Fig. 5). However, there is no thermocouple at the very top and bottom of the bed itself, and the thermal evolutions of the fluid entering the bed and entering the tank are different due to the inertia of the fluid contained in the convex ends. This is illustrated by Fig. 6: at the beginning of a charge, the temperature peak (due to regulation issues) measured in the inlet pipe is completely softened mainly by the convex end and also by the beginning of the bed. Therefore, the thermal evolution of the fluid entering the bed is estimated thanks to the thermocouples measuring the temperature a dozen of centimetres from the end of the packed bed $(z=0.12 \mathrm{~m}$ or $z=2.87 \mathrm{~m}$, measurement levels marked with triangles on Fig. 5). For that purpose, the thermal evolution measured near the end of the packed bed is time-shifted with the offset $\tau$. This offset is proportional to the instantaneous thermal front velocity $u_{T F}$ (equation (22)). This approach assumes that the dozen of centimetres of packed bed between the inlet of the bed and the first level of measurement doesn't affect significantly the shape of the thermal evolution compared to the convex end. Fig. 6 shows that this assumption is reasonable since the thermal evolutions actually measured and predicted by the model (when computed with the estimated temperature evolution at the inlet of the bed) for $z=2.87 \mathrm{~m}$ are very similar. The thermal evolution is only slightly softened but that is assumed negligible. 


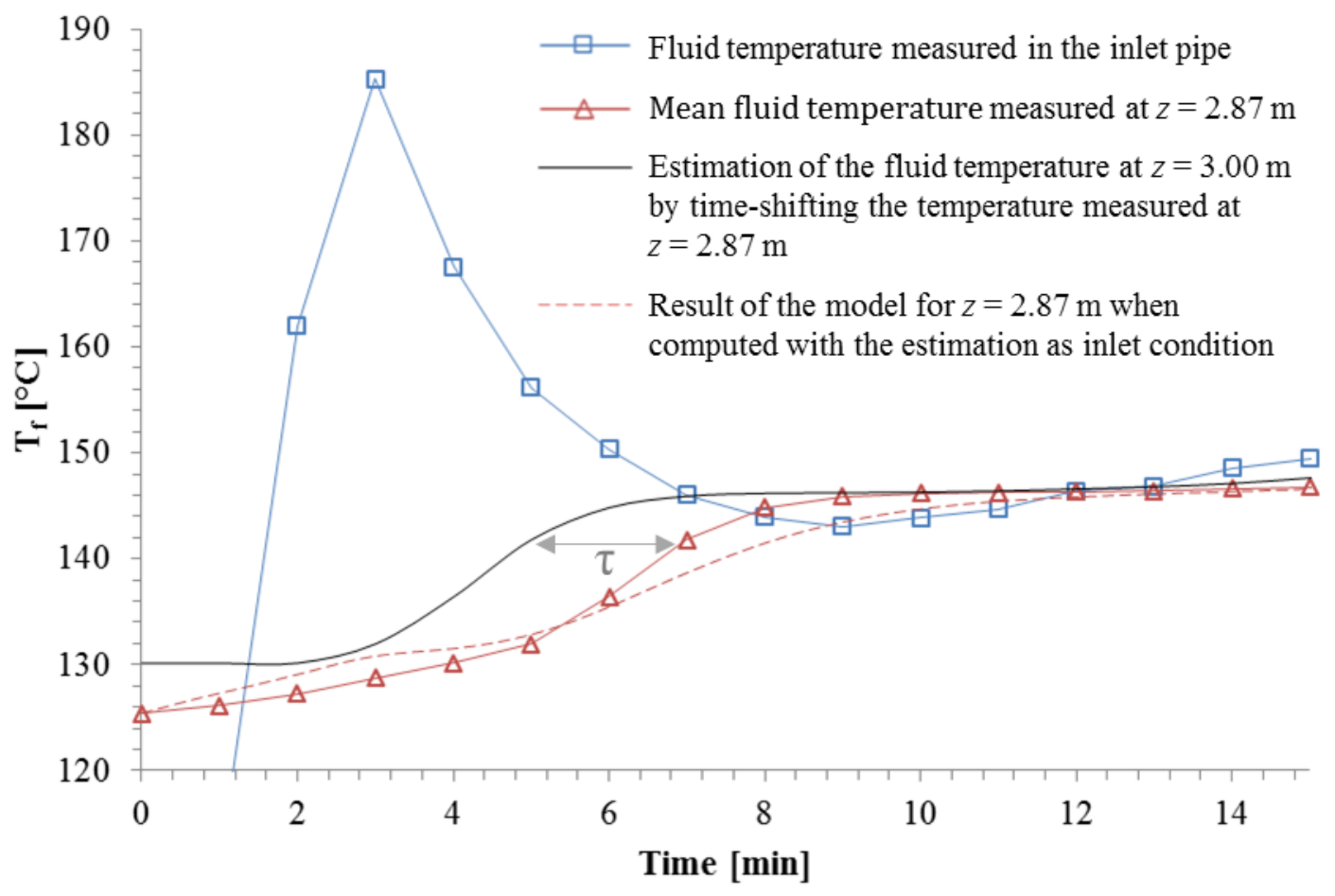

Fig. 6. Temperature evolution of various points of the storage tank at the beginning of a charge.

$$
\tau=\frac{u_{T F}}{\Delta z}=\frac{\frac{\varepsilon \cdot \rho_{f} \cdot c_{p_{f}}}{\varepsilon \cdot \rho_{f} \cdot c_{p_{f}}+x_{r} \cdot \rho_{r} \cdot c_{p_{r}}+x_{s} \cdot \rho_{s} \cdot c_{p_{s}}+x_{w} \cdot \rho_{w} \cdot c_{p_{w}}} \cdot u_{f}}{\Delta z}
$$

By applying this method in order to determine the inlet conditions of the packed bed, the results of the numerical model were compared to experimental data. The model was validated in various cyclic conditions (several temperature levels, charge and discharge rates, fluid flows, etc.).

Fig. 7 shows comparisons of experimental and numerical thermal profiles during charges operated with different fluid velocities. The numerical results of the two versions of the model are presented: the version in which the actual bimodal particle size distribution of the packed bed is accounted for, and the version in which all the packed bed is assumed to consist of rocks only i.e. with a monomodal particle size distribution (which is not the case in reality). The comparisons show that both models give satisfactory results at low fluid velocity (Fig. 7 (a)). However at high fluid velocity (Fig. 7 (b)), the version in which the sand is modelled separately in the energy equation of the fluid gives better results. This shows the relevancy of the bimodal particle size distribution approach: the higher the fluid velocity, the better is the bimodal distribution model compared to the monomodal distribution model. This difference is due to the fact that only the heat exchange between the rocks and the fluid is significantly affected by the fluid velocity, while the fluid/sand heat exchange is almost perfect (thermal equilibrium) until very high fluid velocities. That's why the monomodal approach overestimates the fluid velocity influence and the degradation of the fluid/solid heat exchange and hence predicts too thick thermoclines at high fluid velocity (Fig. 7 (b)).
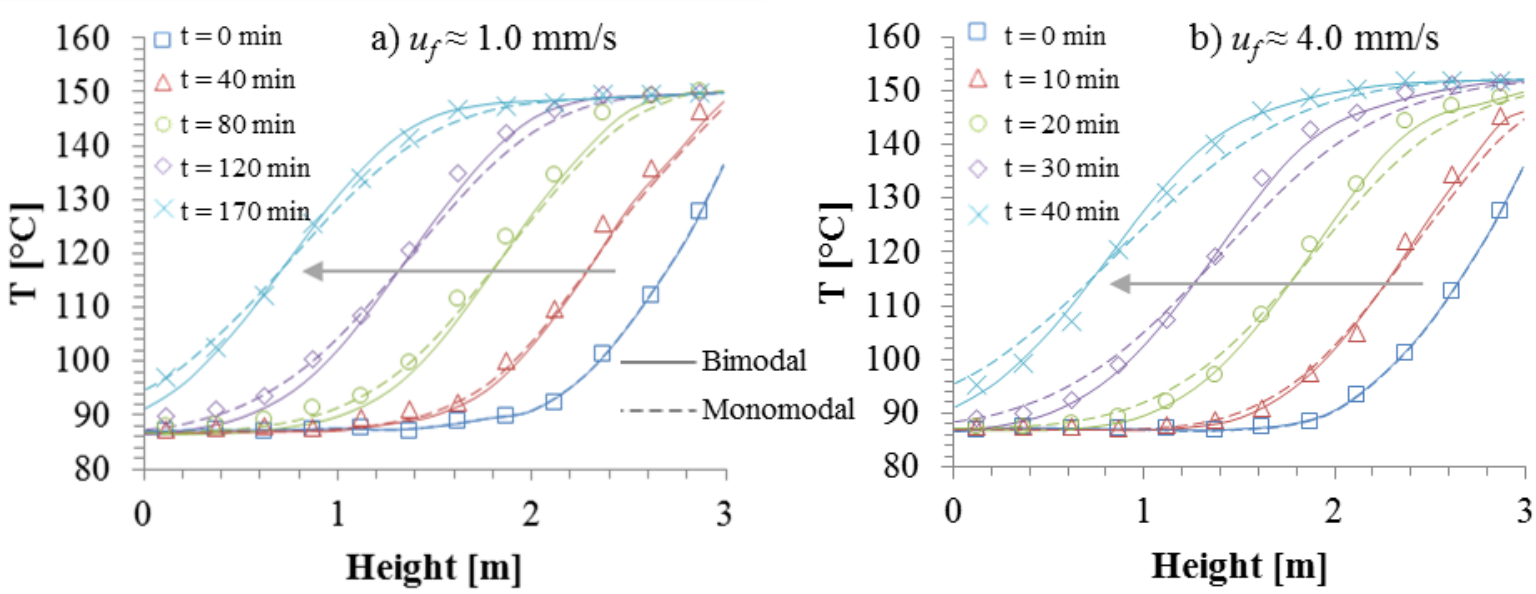

Fig. 7. Comparison of experimental and numerical thermal profiles (respectively symbols and curves) in the storage tank of STONE during charges operated with a fluid velocity of $1.0 \mathrm{~mm} / \mathrm{s}$ (a) and $4.0 \mathrm{~mm} / \mathrm{s}$ (b). The results of the bimodal and the monomodal particle size distribution approaches are presented (respectively continuous and dashed lines). 
Fig. 8 shows an advanced validation of the model. The numerical and the experimental results obtained during various tests of 15 cycles are compared (only the bimodal particle size distribution model is presented). The charge/discharge cycles have been performed between $85{ }^{\circ} \mathrm{C}$ and $150{ }^{\circ} \mathrm{C}$ with extraction of $20 \%$ of the thermocline at the end of charges and $33 \%$ at the end of discharges. There is no standby period between cycles: the flow is inverted a few minutes after the end of each charge/discharge. Each test has been performed with a different fluid velocity (i.e. fluid mass flow). Fig. 8 shows the thermal profiles in the packed bed at the end of some cycles.
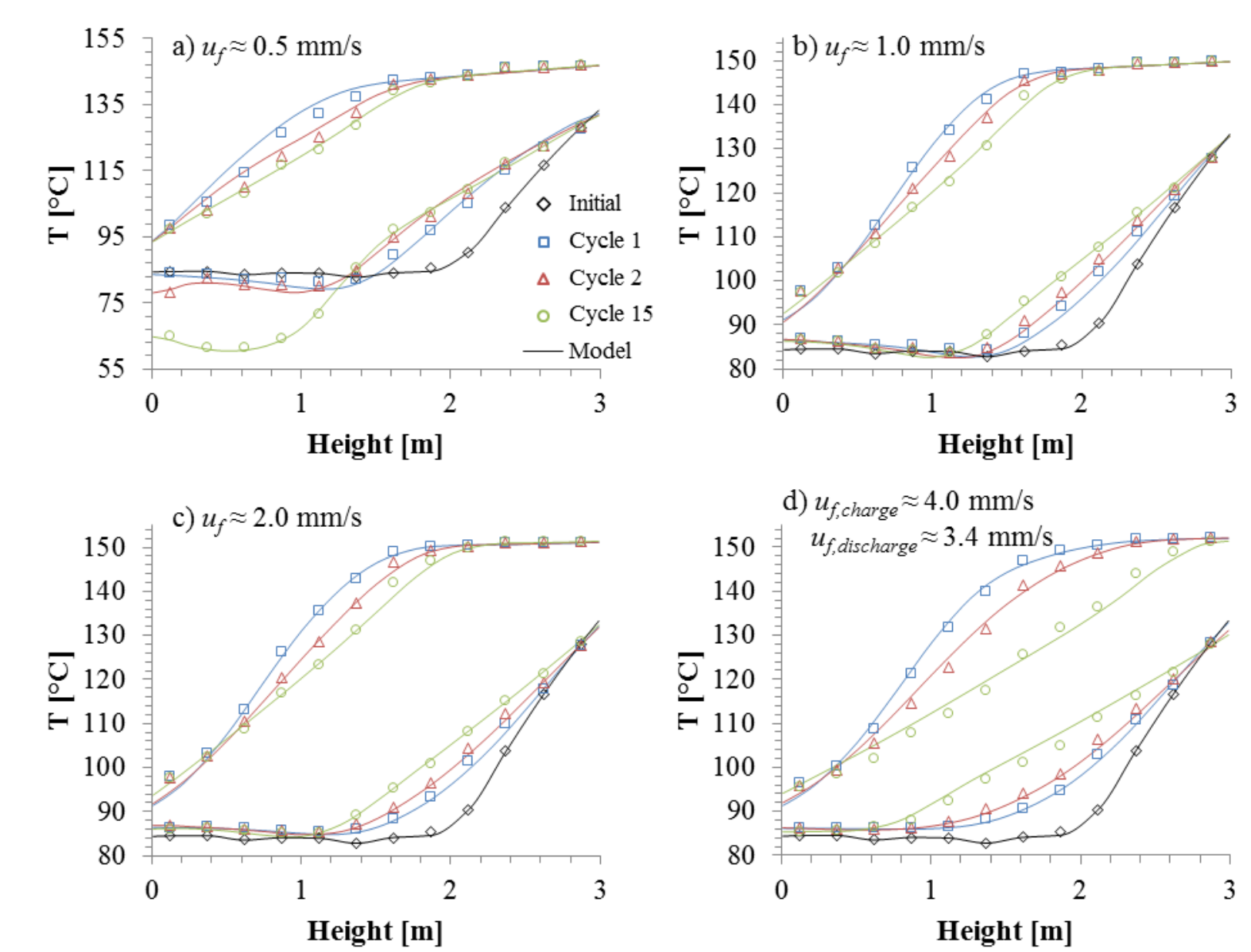

Fig. 8. Comparison of experimental and numerical thermal profiles (respectively symbols and curves) in the storage tank of STONE at the end of charges and discharges through 15 cycles performed between $85^{\circ} \mathrm{C}$ and $150^{\circ} \mathrm{C}$ with various fluid velocities.

In order to obtain the numerical results, the model was initialized from a partially discharged state and computed for each cycle with the evolution of mass flow measured on the setup, the thermal evolution estimated at the inlet of the bed and exactly the same duration as the experimental setup (Table 4). At the end of each charge/discharge, the numerical thermal profile reached by the model is used as initial state to compute the next cycle. The average evolutions of the mass flow and of the inlet temperature are respectively depicted in Fig. 9 and Fig. 10. These averages are very representative of all cycles, except for the inlet temperature of discharge at $0.5 \mathrm{~mm} / \mathrm{s}$ which suffered from regulation problems. If used for modelling, the average evolutions should be cut off before the end when the cycle is shorter than what is depicted on the graphs. To simulate the results presented in Fig. 8, the detailed evolutions specific to each cycle were used. They are published with this paper as supplementary material as well as the detailed thermal profiles at the end of each charge/discharge.

\begin{tabular}{|c|c|c|c|c|c|c|c|c|}
\hline \multirow{2}{*}{ Cycle } & \multicolumn{2}{|c|}{$\mathbf{u}_{\mathbf{f}} \approx \mathbf{0 . 5} \mathbf{~ m m} / \mathbf{s}$} & \multicolumn{2}{c|}{$\mathbf{u}_{\mathbf{f}} \approx \mathbf{1 . 0} \mathbf{~ m m} / \mathbf{s}$} & \multicolumn{2}{c|}{$\mathbf{u f}_{\mathbf{f}} \approx \mathbf{2 . 0} \mathbf{~ m m} / \mathbf{s}$} & \multicolumn{2}{c|}{$\mathbf{u}_{\mathbf{f}} \approx \mathbf{4 . 0}-\mathbf{3 . 4} \mathbf{~ m m} / \mathbf{s}$} \\
\cline { 2 - 10 } & $\mathrm{t}_{\text {charge }}[\mathrm{s}]$ & $\mathrm{t}_{\text {discharge }}[\mathrm{s}]$ & $\mathrm{t}_{\text {charge }}[\mathrm{s}]$ & $\mathrm{t}_{\text {discharge }}[\mathrm{s}]$ & $\mathrm{t}_{\text {charge }}[\mathrm{s}]$ & $\mathrm{t}_{\text {discharge }}[\mathrm{s}]$ & $\mathrm{t}_{\text {charge }}[\mathrm{s}]$ & $\mathrm{t}_{\text {discharge }}[\mathrm{s}]$ \\
\hline 1 & 22140 & 15960 & 10200 & 8520 & 5100 & 4440 & 2460 & 2520 \\
\hline 2 & 18600 & 14040 & 9360 & 7920 & 4620 & 4140 & 2160 & 2340 \\
\hline 3 & 17220 & 13260 & 8880 & 7560 & 4380 & 3960 & 1980 & 2100 \\
\hline 4 & 16920 & 13320 & 8580 & 7380 & 4260 & 3900 & 1920 & 2040 \\
\hline 5 & 16740 & 13080 & 8400 & 7320 & 4140 & 3660 & 1800 & 1860 \\
\hline 6 & 16560 & 13020 & 8280 & 7200 & 4140 & 3660 & 1740 & 1860 \\
\hline 7 & 16440 & 13020 & 8280 & 7140 & 4140 & 3720 & 1680 & 1740 \\
\hline 8 & 16440 & 12960 & 8280 & 7080 & 4140 & 3600 & 1680 & 1740 \\
\hline 9 & 16440 & 12900 & 8280 & 7080 & 4080 & 3660 & 1620 & 1680 \\
\hline
\end{tabular}




\begin{tabular}{|l|l|l|l|l|l|l|l|l|}
\hline 10 & 16320 & 12900 & 8220 & 7080 & 4140 & 3660 & 1560 & 1680 \\
\hline 11 & 16320 & 12840 & 8220 & 7080 & 4080 & 3660 & 1560 & 1620 \\
\hline 12 & 16320 & 12780 & 8280 & 7080 & 4140 & 3600 & 1500 & 1620 \\
\hline 13 & 16380 & 12840 & 8280 & 7020 & 4140 & 3660 & 1560 & 1560 \\
\hline 14 & 16560 & 12780 & 8220 & 7080 & 4080 & 3660 & 1500 & 1560 \\
\hline 15 & 16800 & 12900 & 8220 & 7080 & 4080 & 3600 & 1500 & 1560 \\
\hline
\end{tabular}

Table 4. Duration of each cycle of each test.

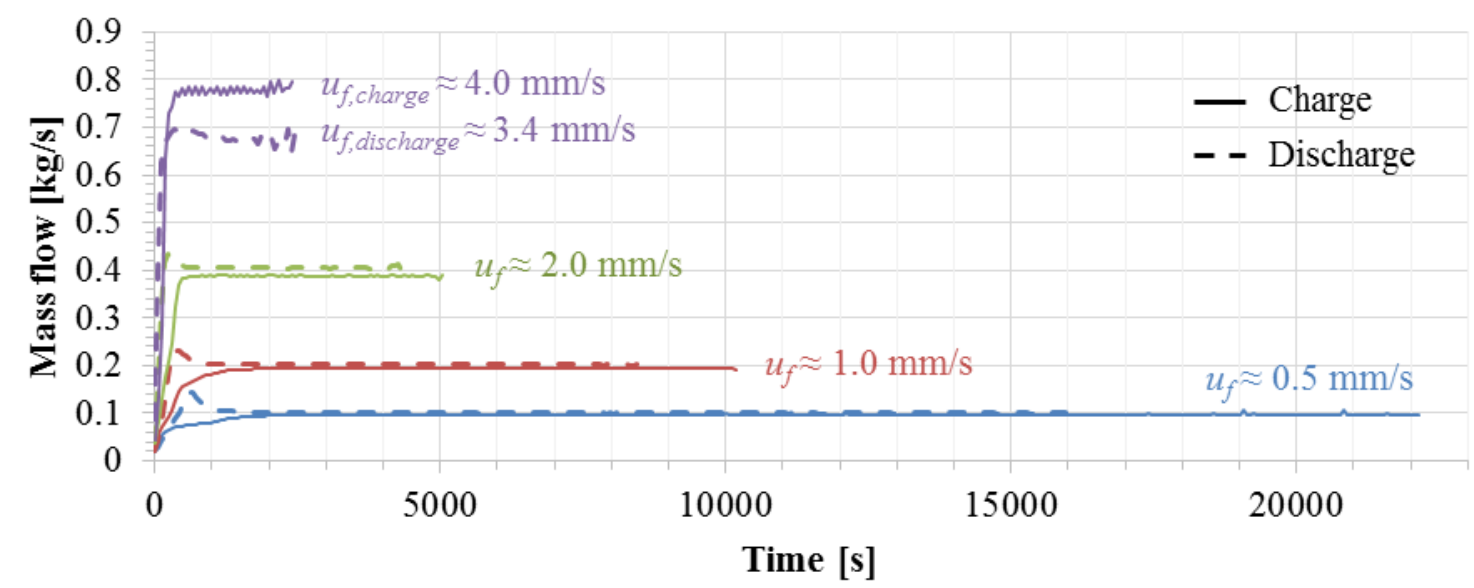

Fig. 9. Average evolution of the fluid mass flow during charge and discharge of each test.

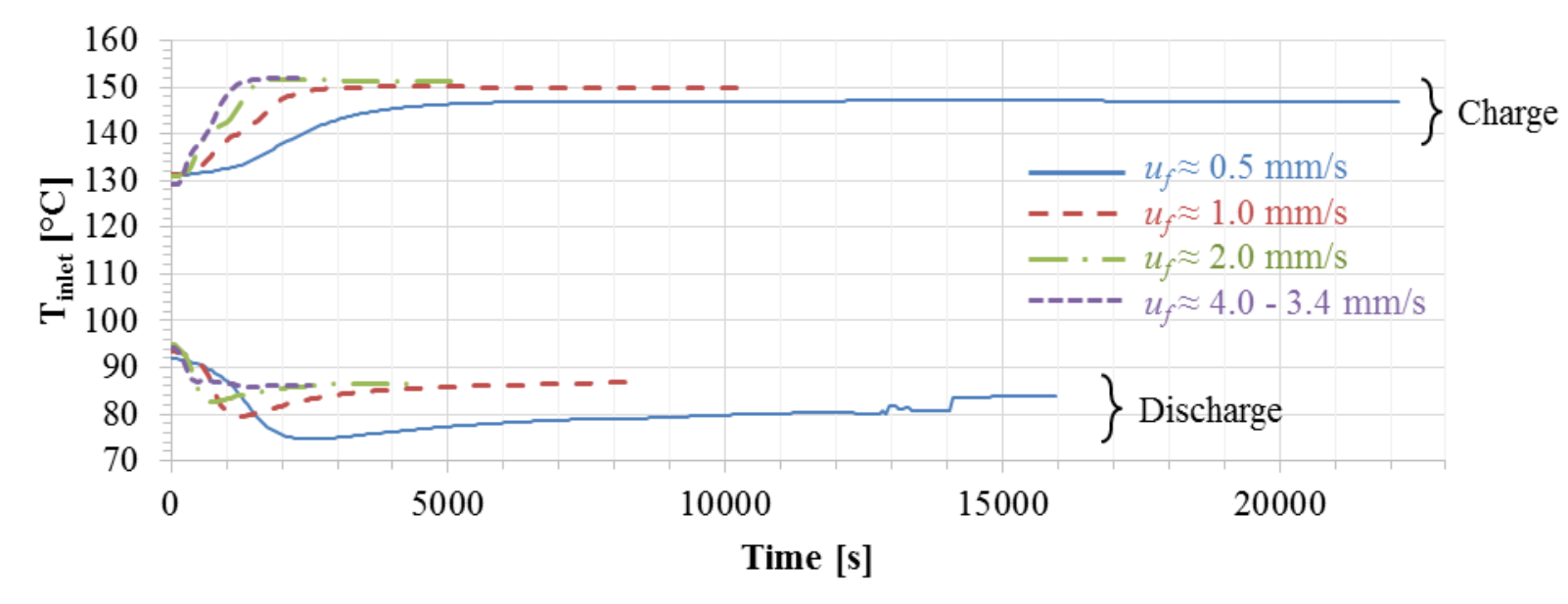

Fig. 10. Average evolution of the inlet temperature of the bed during charge and discharge of each test.

These results show that the model is able to predict the behaviour of the storage in cyclic conditions through many cycles until stabilization. Even when there are fluctuations of the inlet temperature due to regulation issues (like for the $15^{\text {th }}$ cycle in Fig. 8 (a)), the model is able to describe the resulting behaviour of the system. That means that the methodology used to estimate the thermal evolution of the inlet fluid is efficient. Moreover, the model predicts correctly the influence of the fluid velocity (from 0.5 to $4.0 \mathrm{~mm} / \mathrm{s}$ ), which means that the approach used to account for the bimodal particle size distribution and the correlations used to compute the heat transfer coefficients (which are influenced by the fluid velocity) are relevant.

It is difficult to use the experimental data in order to study the single influence of the fluid velocity because some tests suffered from regulation problems and the inlet conditions are different for each test. For example, the stabilized thermocline is much thicker at high fluid velocity (Fig. 8 (d)) compared to the other tests. However, this could be partially explained by the evolution of the inlet fluid temperature: the thermal evolution of the inlet fluid consists mainly of a slope (especially during the last cycles of the test) and is very far from an ideal temperature step (cf. Fig. 10). At low velocity, this effect is not as important, that's why the resulting thermocline is thinner.

\section{Numerical study of the fluid velocity influence}

Since the model has been validated in various operating conditions, it is possible to use it in order to perform a numerical study of the fluid velocity influence. This study consists in modelling a system similar to STONE with the same kind of test as Fig. 8 but with ideal inlet conditions, i.e. with temporal steps of mass flow and fluid temperature. Like for experimental tests, there is no standby period between cycles. Fig. 11 shows the stabilized thermal profiles at the end of charges and discharges when cycling is operated with various mass fluid flows (each one corresponding to an average fluid velocity). Even if the model has been validated only with a fluid velocity up to $4 \mathrm{~mm} / \mathrm{s}$, the numerical study is extrapolated up to $10 \mathrm{~mm} / \mathrm{s}$. The model is assumed still valid at this velocity but the results should be considered with precaution. This extrapolation only enables to highlight the trends. 


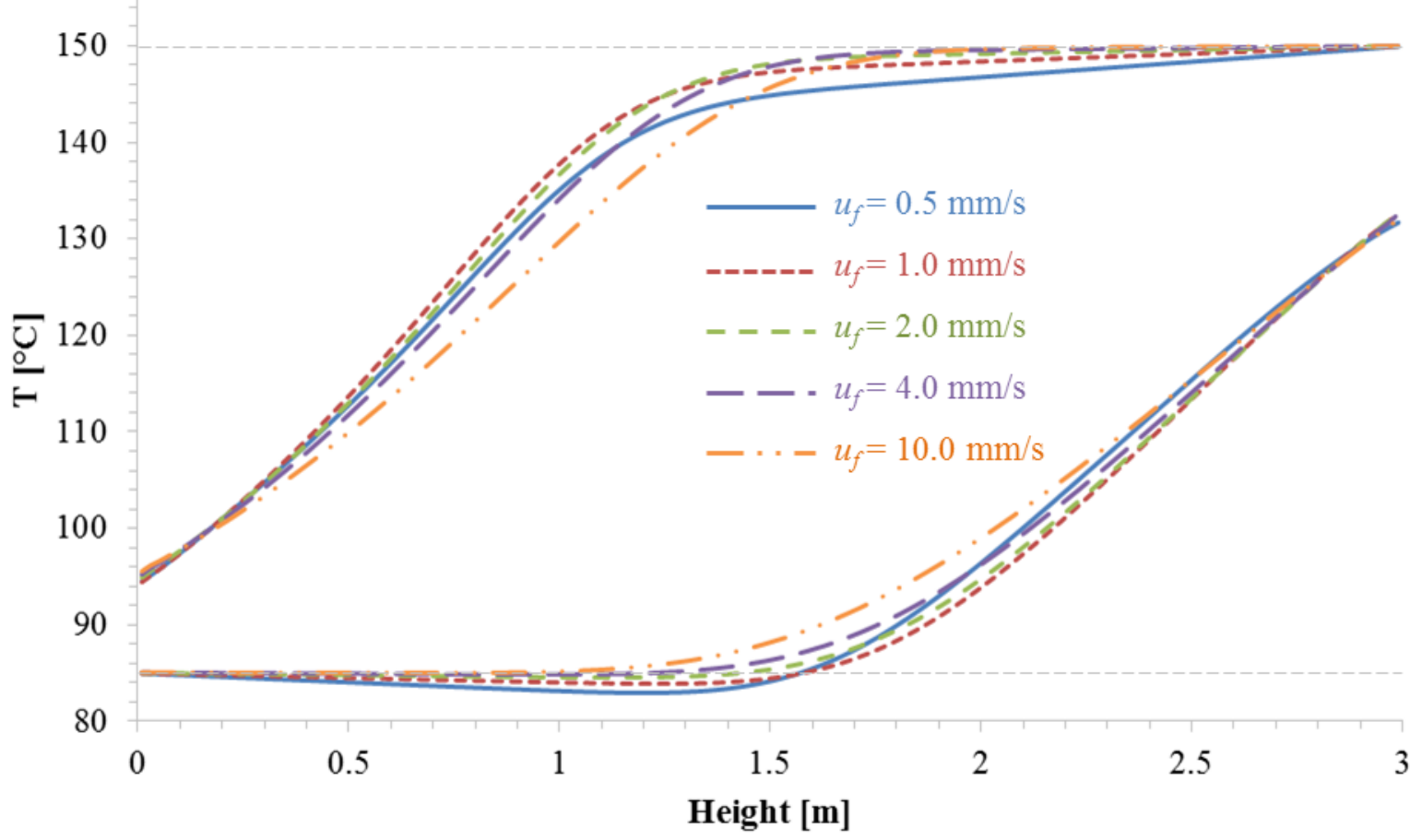

Fig. 11. Numerical stabilized thermal profiles after cycling between $85^{\circ} \mathrm{C}$ and $150^{\circ} \mathrm{C}$ with ideal inlet conditions and various fluid velocities $\left(U_{w / \infty}=1.55 \mathrm{~W} \cdot \mathrm{m}^{-2} \cdot \mathrm{K}^{-1}\right)$.

Fig. 12 shows some parameters calculated with the numerical results. Fig. 12 (a) shows the net charged and discharged energies during a stabilized cycle for several fluid velocities. These energies are calculated thanks to equation (23). The efficiency which is the ratio of both values is also plotted. This graph highlights the influence of the fluid velocity on thermal losses. At low fluid velocity, the residence time of fluid in the tank is higher and the fluid undergoes more thermal losses. Therefore, it is necessary to input more energy during charge to reach a given temperature at the bottom of the storage and less energy is available during discharge since a part of energy is lost to the outside. This leads to a reduction of the efficiency. At high fluid velocity, the residence time of fluid is short and thermal losses are reduced, which leads to an efficiency close to $100 \%$. It should be noted that it is possible because there is no standby period and hence no thermal losses between a charge and the consecutive discharge.

$$
\mathrm{E}=\int_{0}^{\mathrm{t}}\left|\left(\dot{\mathrm{m}} \cdot \mathrm{c}_{\mathrm{p}_{\mathrm{f}}} \cdot \mathrm{T}_{\mathrm{f}}\right)_{\text {inlet }}-\left(\dot{\mathrm{m}} \cdot \mathrm{c}_{\mathrm{p}_{\mathrm{f}}} \cdot \mathrm{T}_{\mathrm{f}}\right)_{\text {outlet }}\right| \cdot d \mathrm{t}
$$

However, the fluid velocity also influences the thermal stratification of the storage, i.e. the slope of the thermocline. At low fluid velocity, the fluid/solid heat exchange is closer to ideality and fluid mixing (modelled through equation (20)) is lower. That's why low fluid velocities tend to improve stratification. A good thermal stratification enables to store more energy in the storage. This may be assessed thanks to the utilization rate defined as the ratio between the energy actually discharged during a stabilized cycle and the theoretical energy capacity of the storage $\left(94.8 \mathrm{kWh}\right.$ for STONE between $85^{\circ} \mathrm{C}$ and $\left.150^{\circ} \mathrm{C}\right)$. Fig. 12 (b) shows the evolution of the utilization rate versus fluid velocity. The reference case (corresponding to Fig. 11 and Fig. 12 (a)) corresponds to $U_{w / \infty}=1.55 \mathrm{~W} \cdot \mathrm{m}^{-2} \cdot \mathrm{K}^{-1}$ (same heat loss coefficient as STONE). The utilization rates corresponding to an ideally insulated tank $\left(U_{w / \infty}=0 \mathrm{~W} \cdot \mathrm{m}^{-2} \cdot \mathrm{K}^{-1}\right)$ and to a heat loss coefficient three times higher $\left(U_{w / \infty}=4.65 \mathrm{~W} \cdot \mathrm{m}^{-2} \cdot \mathrm{K}^{-1}\right)$ are also plotted. Fig. 12 (b) shows that there is an optimal fluid velocity which enables to maximize the utilization rate. The optimal velocity corresponds to a compromise mainly between heat losses and stratification. Above the optimal velocity the utilization rate decreases due to de-stratification caused by non-ideal fluid/solid heat exchange and fluid mixing: the thickness of the thermocline increases (Fig. 11). Below the optimal velocity, the utilization rate decreases mainly due to thermal losses. This is visible in Fig. 11: at the end of charges the upper part of the storage is not at the nominal hot temperature due to thermal losses.

Fig. 12 (b) shows that the lower the heat loss coefficient, the lower is the optimal velocity and the higher is the corresponding utilization rate. However, thermal losses are not the only phenomenon which reduces the utilization rate at low fluid velocity. Fig. 12 (b) shows that even if the tank is perfectly insulated $\left(U_{w / \infty}=0 \mathrm{~W} \cdot \mathrm{m}^{-2} \cdot \mathrm{K}^{-1}\right)$, at very low fluid velocity, thermal diffusion in the packed bed increases the thermocline thickness and leads to a reduction of the utilization rate. 


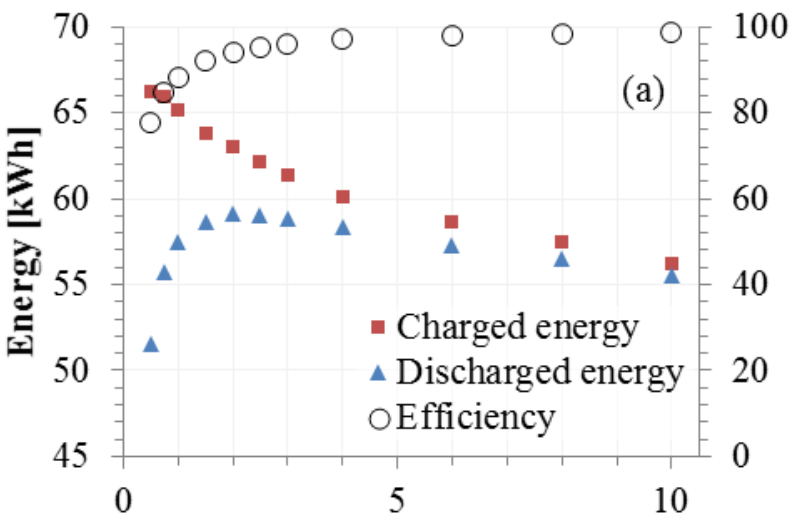

Fluid velocity $[\mathrm{mm} / \mathrm{s}]$

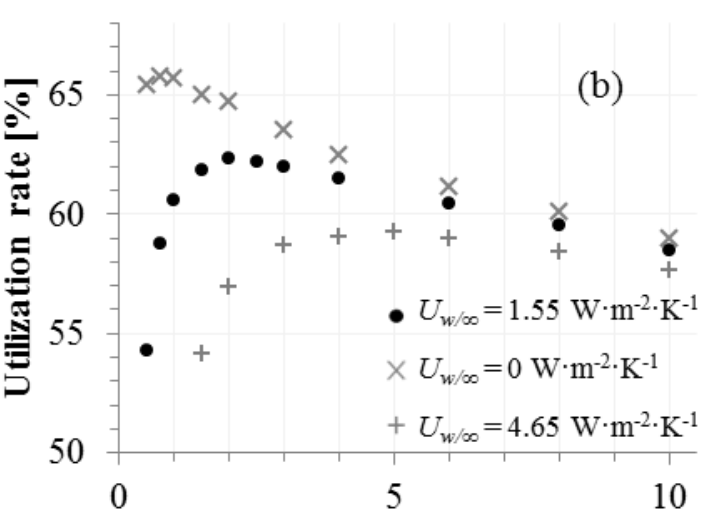

Fluid velocity $[\mathrm{mm} / \mathrm{s}]$

Fig. 12. Influence of the fluid velocity. (a) Net charged and discharged energies and efficiency versus fluid velocity $\left(U_{w / \infty}=1.55 \mathrm{~W} \cdot \mathrm{m}^{-2} \cdot \mathrm{K}^{-1}\right)$. (b) Utilization rate of the storage versus fluid velocity with several heat loss coefficients.

\section{Conclusion}

Thanks to comparisons with different experimental data, the developed one-dimensional three-phase model has been validated in various experimental conditions. It is able to describe the thermal behaviour of packed-bed heat storage systems running with either liquid or gaseous heat transfer fluids. Thanks to the extended lumped capacity method it is possible to keep the continuous porous medium approach introduced by Schumann, 1929, even when the Biot number of the solids is large. When a fraction of the packed bed consists of fine particles like sand, which is common in the literature, the heat capacity of these solids is simply accounted for in the energy equation of the fluid by assuming thermal equilibrium. This approach is efficient and enables to describe more accurately the influence of the fluid velocity. The correlations selected to compute the heat transfer coefficients in each case (monomodal or bimodal particle size distribution) are likely to be general enough to enable the modelling of various configurations and flow regimes (i.e. fluid velocities) without fitting or adjustment. This has been shown by the validation with the data from the STONE experimental loop.

The validated model has been used to perform a study about the influence of the fluid velocity in a system with a liquid as heat transfer fluid. The higher the velocity, the lower are heat losses and thermal diffusion of the thermocline due to the reduction of the residence time of fluid. However, when the fluid velocity is increased the fluid/solid heat exchange is degraded and the thermocline thickness increase. As a consequence, there is a fluid velocity which enables to maximize the utilization rate of the storage and which corresponds to a compromise between these two contradictory influences. The higher the heat losses and the effective conductivity of the bed, the higher is the optimal velocity and the lower is the corresponding maximum utilization rate. This study shows how such a model could be used to design and investigate packed bed heat storage systems. In future work, further validation of this model thanks to experimental data from high temperature gas/solid structured and granular packed beds will be presented.

\section{Nomenclature}

\begin{tabular}{|c|c|}
\hline \multicolumn{2}{|r|}{ Latin characters } \\
\hline$a_{b}$ & external surface area of bed per unit bed volume $\left(\mathrm{m}^{2} \cdot \mathrm{m}^{-3}\right)$ \\
\hline $\mathrm{a}_{\mathrm{r}}$ & surface area of solid per unit bed volume $\left(\mathrm{m}^{2} \cdot \mathrm{m}^{-3}\right)$, see equations $(5)$ and (11) \\
\hline$a_{w, e x t}$ & external surface area of wall per unit wall volume $\left(\mathrm{m}^{2} \cdot \mathrm{m}^{-3}\right)$ \\
\hline$a_{w, i n t}$ & internal surface area of wall per unit wall volume $\left(\mathrm{m}^{2} \cdot \mathrm{m}^{-3}\right)$ \\
\hline B & deformation factor of the solids \\
\hline $\mathrm{Bi}$ & dimensionless Biot number, $\mathrm{Bi}=\mathrm{h}_{\mathrm{r}} \cdot \mathrm{D}_{\mathrm{eq}, \mathrm{a}, \mathrm{r}} / \lambda_{\mathrm{r}}$ \\
\hline $\mathrm{C}$ & empirical constant in the correlation of Zehner and Schlünder, 1970 \\
\hline$c_{\mathrm{p}}$ & specific heat capacity $\left(\mathrm{J} \cdot \mathrm{kg}^{-1} \cdot \mathrm{K}^{-1}\right)$ \\
\hline $\mathrm{D}_{\mathrm{b}}$ & diameter of the bed, i.e. internal diameter of the tank (m) \\
\hline $\mathrm{D}_{\mathrm{eq}, \mathrm{A}, \mathrm{r}}$ & diameter of the sphere with the same surface as the solids (m) \\
\hline $\mathrm{D}_{\mathrm{eq}, \mathrm{a}, \mathrm{r}}$ & diameter of the sphere with the same volume to surface ratio as the solids (m) \\
\hline $\mathrm{D}_{\mathrm{eq}, \mathrm{V}, \mathrm{r}}$ & diameter of the sphere with the same volume as the solids (m) \\
\hline$D_{s}$ & diameter of the sand grains (m) \\
\hline
\end{tabular}




\begin{tabular}{|c|c|}
\hline $\mathrm{e}_{\mathrm{w}}$ & wall thickness $(\mathrm{m})$ \\
\hline $\mathrm{E}$ & energy $(\mathrm{J})$ \\
\hline $\mathrm{f}$ & term of tortuosity, defined in Cheng and Hsu, 1998 \\
\hline $\mathrm{h}$ & heat transfer coefficient $\left(\mathrm{W} \cdot \mathrm{m}^{-2} \cdot \mathrm{K}^{-1}\right)$ \\
\hline $\mathrm{L}_{\mathrm{b}}$ & length of the packed bed in flow direction (m) \\
\hline$\dot{\mathrm{m}}$ & fluid mass flow $\left(\mathrm{kg} \cdot \mathrm{s}^{-1}\right)$ \\
\hline $\mathrm{Nu}$ & dimensionless Nusselt number \\
\hline $\operatorname{Pr}$ & dimensionless Prandtl number, $\operatorname{Pr}=\mu_{\mathrm{f}} \cdot \mathrm{c}_{\mathrm{p}_{\mathrm{f}}} / \lambda_{\mathrm{f}}$ \\
\hline $\mathrm{R}_{\mathrm{b}}$ & radius of the bed $(m), R_{b}=D_{b} / 2$ \\
\hline $\operatorname{Re}$ & dimensionless Reynolds number, see equations (7) and (13) \\
\hline $\mathrm{T}$ & temperature $\left({ }^{\circ} \mathrm{C}, \mathrm{K}\right)$ \\
\hline $\mathrm{t}$ & time (s) \\
\hline$t^{*}$ & dimensionless time, $\mathrm{t}^{*}=\mathrm{t} / \mathrm{t}_{\text {total }}$ \\
\hline$t_{a d v}$ & characteristic time of advection $(\mathrm{s}), \mathrm{t}_{\mathrm{adv}}=\mathrm{D}_{\mathrm{s}} / \mathrm{u}_{\mathrm{f}}$ \\
\hline$t_{\text {cond }}$ & characteristic time of conduction within particles $(\mathrm{s}), \mathrm{t}_{\text {cond }}=\mathrm{D}_{\mathrm{s}}{ }^{2} /\left(36 \cdot \alpha_{\mathrm{s}}\right)$ \\
\hline $\mathrm{u}_{\mathrm{f}}$ & interstitial fluid velocity $\left(\mathrm{m} \cdot \mathrm{s}^{-1}\right), \mathrm{u}_{\mathrm{f}}=\dot{\mathrm{m}} /\left(\rho_{\mathrm{f}} \cdot \varepsilon \cdot \pi \cdot \mathrm{R}_{\mathrm{b}}^{2}\right)$ \\
\hline $\mathrm{u}_{\mathrm{TF}}$ & velocity of the thermal front $\left(\mathrm{m} \cdot \mathrm{s}^{-1}\right)$ \\
\hline $\mathrm{U}_{\mathrm{w} / \infty}$ & $\begin{array}{l}\text { heat loss coefficient, i.e. overall heat transfer coefficient between the external surface of the } \\
\text { tank's wall and the outside }\left(\mathrm{W} \cdot \mathrm{m}^{-2} \cdot \mathrm{K}^{-1}\right)\end{array}$ \\
\hline $\mathrm{x}$ & volume fraction compared to the bed volume \\
\hline $\mathrm{z}$ & axial coordinate in flow direction $(\mathrm{m})$ \\
\hline \multicolumn{2}{|r|}{ Greek characters } \\
\hline$\alpha$ & thermal diffusivity $\left(\mathrm{m}^{2} \cdot \mathrm{s}^{-1}\right), \alpha=\lambda /\left(\rho \cdot \mathrm{c}_{\mathrm{p}}\right)$ \\
\hline$\varepsilon$ & void fraction of the bed, i.e. volume fraction of fluid \\
\hline$\epsilon$ & emissivity \\
\hline$\lambda$ & thermal conductivity $\left(\mathrm{W} \cdot \mathrm{m}^{-1} \cdot \mathrm{K}^{-1}\right)$ \\
\hline$\lambda_{\mathrm{eff}}^{0}$ & $\begin{array}{l}\text { effective thermal conductivity of the packed bed due to the conduction in the fluid and the solids } \\
\text { in stagnant fluid condition without thermal radiation }\left(\mathrm{W} \cdot \mathrm{m}^{-1} \cdot \mathrm{K}^{-1}\right)\end{array}$ \\
\hline$\mu$ & dynamic viscosity $(\mathrm{Pa} \cdot \mathrm{s})$ \\
\hline$v$ & cinematic viscosity $\left(\mathrm{m}^{2} \cdot \mathrm{s}^{-1}\right)$ \\
\hline$\rho$ & density $\left(\mathrm{kg} \cdot \mathrm{m}^{-3}\right)$ \\
\hline$\sigma$ & Stephan-Boltzmann constant, $\sigma=5.67 \cdot 10^{-8} \mathrm{~W} \cdot \mathrm{m}^{-2} \cdot \mathrm{K}^{-4}$ \\
\hline$\tau$ & offset corresponding to the transit time of the thermal front (s) \\
\hline$\Psi_{\mathrm{r}}$ & $\begin{array}{l}\text { sphericity of the solids, i.e. surface of the sphere with the same volume divided by the actual } \\
\text { surface of the solid }\end{array}$ \\
\hline \multicolumn{2}{|r|}{ Subscripts } \\
\hline$\infty$ & relating to ambient \\
\hline $\mathrm{b}$ & bed (fluid + solids) \\
\hline eff & effective \\
\hline f & fluid \\
\hline inlet & inlet of the packed bed \\
\hline outlet & outlet of the packed bed \\
\hline $\mathrm{r}$ & rocks or solids \\
\hline $\mathrm{s}$ & sand \\
\hline $\mathrm{w}$ & wall of the tank \\
\hline
\end{tabular}




\section{References}

Beasley, D.E., Clark, J.A., 1984. Transient response of a packed bed for thermal energy storage. Int. J. Heat Mass Transf. 27, 1659-1669. https://doi.org/10.1016/0017-9310(84)90278-3

Breitbach, G., Barthels, H., 1980. The radiant heat transfer in the HTR core after failure of the afterheat removal systems. Nucl. Technol. 49, 392-399.

Brosseau, D., Kelton, J.W., Ray, D., Edgar, M., Chisman, K., Emms, B., 2005. Testing of thermocline filler materials and molten-salt heat transfer fluids for thermal energy storage systems in parabolic trough power plants. J. Sol. Energy Eng. Trans. ASME 127, 109-116. https://doi.org/10.1115/1.1824107

Bruch, A., Fourmigué, J.F., Couturier, R., 2014. Experimental and numerical investigation of a pilot-scale thermal oil packed bed thermal storage system for CSP power plant. Sol.Energy 105, 116-125. https://doi.org/10.1016/j.egypro.2014.03.080

Bruch, A., Molina, S., Esence, T., Fourmigué, J.F., Couturier, R., 2017. Experimental investigation of cycling behaviour of pilot-scale thermal oil packed-bed thermal storage system. Renew. Energy 103, 277-285.

https://doi.org/10.1016/j.renene.2016.11.029

Cascetta, M., Cau, G., Puddu, P., Serra, F., 2016. A comparison between CFD simulation and experimental investigation of a packed-bed thermal energy storage system. Appl. Therm. Eng. 98, 1263-1272.

Cheng, P., Hsu, C.T., 1998. Heat conduction, in: Ingham, D.B., Pop, I. (Eds.), Transport Phenomena in Porous Media. Pergamon, pp. 57-76.

Cocco, D., Serra, F., 2015. Performance comparison of two-tank direct and thermocline thermal energy storage systems for 1MWe class concentrating solar power plants. Energy 81, 526-536. https://doi.org/10.1016/j.energy.2014.12.067

Dixon, A.G., DiCostanzo, M.A., Soucy, B.A., 1984. Fluid-phase radial transport in packed beds of low tube-to-particle diameter ratio. Int. J. Heat Mass Transf. 27, 1701-1713. https://doi.org/10.1016/0017-9310(84)90153-4

Esence, T., Bruch, A., Molina, S., Stutz, B., Fourmigué, J.F., 2017. A review on experience feedback and numerical modeling of packed-bed thermal energy storage systems. Sol. Energy 153, 628-654. https://doi.org/10.1016/j.solener.2017.03.032

Flueckiger, S.M., Iverson, B.D., Garimella, S.V., Pacheco, J.E., 2014. System-level simulation of a solar power tower plant with thermocline thermal energy storage. Appl. Energy 113, 86-96. https://doi.org/10.1016/j.apenergy.2013.07.004

Hallet, R.W.J., Gervais, R.L., 1977. Central receiver solar thermal power system - Phase 1 - CDRL ITEM 2 - Pilot Plant Preliminary Design Report - Vol V - Thermal Storage Subsystem.

Handley, D., Heggs, P.J., 1969. The effect of thermal conductivity of the packing material on transient heat transfer in a fixed bed. Int. J. Heat Mass Transf. 12, 549-570.

Hoffmann, J.F., Fasquelle, T., Goetz, V., Py, X., 2016. A thermocline thermal energy storage system with filler materials for concentrated solar power plants: Experimental data and numerical model sensitivity to different experimental tank scales. Appl. Therm. Eng. 100, 753-761.

Hsu, C.T., Cheng, P., Wong, K.W., 1994. Modified Zehner-Schlunder models for stagnant thermal conductivity of porous media. Int. J. Heat Mass Transf. 37, 2751-2759.

Krumbein, W.C., Sloss, L.L., 1963. Stratigraphy and Sedimentation. Freeman,W.H. \& Co, San Francisco, CA.

Libby, C., 2010. Solar thermocline storage systems: preliminary design study. EPRI.

McDonnell Douglas Astronautics Company, 1986. 10 MWe Solar Thermal Central Receiver Pilot Plant Mode 5 (Test 1150) and Mode 6 (Test 1160) Test report. Sandia National Laboratories.

Nissen, D.A., 1982. Thermophysical Properties of the Equimolar Mixture NaNO3-KNO3 from 300 to $600{ }^{\circ} \mathrm{C}$. J. Chem. Eng. Data 27, 269-273.

Pacheco, J.E., Showalter, S.K., Kolb, W.J., 2002. Development of a molten-salt thermocline thermal storage system for parabolic trough plants. J. Sol. Energy Eng. Trans. ASME 124, 153-159. https://doi.org/10.1115/1.1464123 
Sabihuddin, S., Kiprakis, A.E., Mueller, M., 2015. A numerical and graphical review of energy storage technologies. Energies 8, 172-216. https://doi.org/10.3390/en8010172

Schumann, T.E.W., 1929. Heat transfer: A liquid flowing through a porous prism. J. Frankl. Inst. 208, 405-416.

Van Antwerpen, W., Du Toit, C.G., Rousseau, P.G., 2010. A review of correlations to model the packing structure and effective thermal conductivity in packed beds of mono-sized spherical particles. Nucl. Eng. Des. 240, 1803-1818. https://doi.org/10.1016/j.nucengdes.2010.03.009

Wakao, N., Kaguei, S., 1982. Heat and mass transfer in packed beds. Gordon and Breach Science Publishers, New York.

Wakao, N., Kaguei, S., Funazkri, T., 1979. Effect of fluid dispersion coefficients on particle-to-fluid heat transfer coefficients in packed beds. Correlation of nusselt numbers. Chem.Eng.Sci. 34, 325-336. https://doi.org/10.1016/0009-2509(79)85064-2

Xu, B., Li, P.W., Chan, C.L., 2012. Extending the validity of lumped capacitance method for large Biot number in thermal storage application. Sol.Energy 86, 1709-1724. https://doi.org/10.1016/j.solener.2012.03.016

Zehner, P., Schlünder, E.U., 1970. Wärmeleitfähigkeit von Schüttungen bei mäßigen Temperaturen. Chem. Ing. Tech. 42, 933-941. https://doi.org/10.1002/cite.330421408

\section{Appendix A}

Over a representative sample of $N$ particles, the average diameter of the sphere of equivalent volume can be determined thanks to equation (A.1). The individual volume $V_{r}$ of each particle can be easily measured thanks to the fluid displacement method.

$$
\mathrm{D}_{\mathrm{eq}, \mathrm{V}, \mathrm{r}}=\left(\frac{6}{\pi} \cdot \frac{\sum_{\mathrm{i}}^{\mathrm{N}} \mathrm{V}_{\mathrm{r}, \mathrm{i}}}{\mathrm{N}}\right)^{1 / 3}
$$

Then, it is possible to estimate the diameters of the other equivalent spheres thanks to the average sphericity (see equations (A.2) and (A.3)) which is the ratio between the surface of the sphere of equivalent volume and the actual surface of the particle. For irregular shapes, the sphericity can be estimated thanks to the diagram of Krumbein and Sloss, 1963 (Fig. 13).

$$
\begin{gathered}
\mathrm{D}_{\mathrm{eq}, \mathrm{A}, \mathrm{r}}=\frac{\mathrm{D}_{\mathrm{eq}, \mathrm{V}, \mathrm{r}}}{\sqrt{\Psi_{\mathrm{r}}}} \\
\mathrm{D}_{\mathrm{eq}, \mathrm{a}, \mathrm{r}}=\Psi_{\mathrm{r}} \cdot \mathrm{D}_{\mathrm{eq}, \mathrm{V}, \mathrm{r}}
\end{gathered}
$$

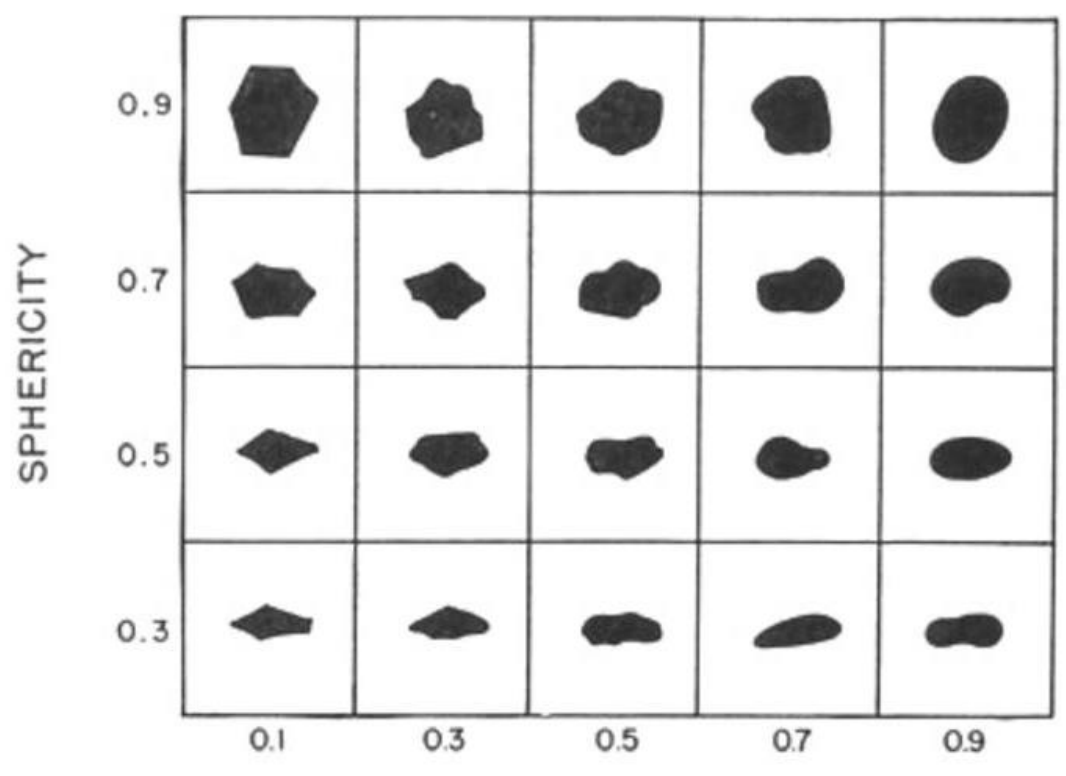

ROUNDNESS

Fig. 13. Diagram for visual estimation of the sphericity and the roundness of irregular particles (Krumbein and Sloss, 1963). 